
\title{
$\begin{array}{ll}\text { Research Square } & \begin{array}{l}\text { Preprints are preliminary reports that have not undergone peer review. } \\ \text { They should not be considered conclusive, used to inform clinical practice, } \\ \text { or referenced by the media as validated information. }\end{array}\end{array}$ \\ Improvement of N-Type Crystalline Silicon Solar Cell Performance Using Novel Texturization Method.
}

\section{Soma Ray}

MSIT: Meghnad Saha Institute of Technology

Anup Mondal

IIEST Shibpur: Indian Institute of Engineering Science and Technology

Utpal Gangopadhyay ( $\square$ utpal_ganguly@yahoo.com )

Meghnad Saha Institute of Technology https://orcid.org/0000-0003-2205-0087

\section{Research Article}

Keywords: diamond cut mono-crystalline silicon, $\mathrm{KOH}-\mathrm{IPA}-\mathrm{NaOCL}$ texturing, reflectivity.

Posted Date: March 10th, 2021

DOI: https://doi.org/10.21203/rs.3.rs-254670/v1

License: (1) This work is licensed under a Creative Commons Attribution 4.0 International License.

Read Full License 


\title{
Improvement of n-Type Crystalline Silicon Solar Cell Performance using Novel Texturization Method.
}

\author{
Soma Ray ${ }^{1,2}$, Anup Mondal ${ }^{2,3}$, Utpal Gangopadhyay $^{1}$. \\ ${ }^{1}$ Meghnad Saha Institute of Technology, Nazirabad, Uchhepota, Via-Sonarpur, Kolkata-700150, West Bengal, India \\ ${ }^{2}$ Centre of Excellence for Green Energy and Sensor Systems, IIEST, Shibpur, Howrah-711103, India \\ ${ }^{3}$ Departments of Chemistry, IIEST, Shibpur, Howrah-711103, West Bengal, India.
}

\begin{abstract}
Texturization of diamond cut crystalline silicon wafers undergoes a great difficulty due to deep saw marks on all over the surface of the wafer which makes hindrance to manufacture high efficiency solar cell. Textural result is not satisfactory after conventional texturization by potassium hydroxide $(\mathrm{KOH})$-isopropyl alcohol (IPA) followed by the saw damage removal by sodium hydroxide $(\mathrm{NaOH})$ aqueous solution. The non-uniform texture surface has been observed with noticeable spots on the wafer surface. Surface texturization of diamond cut silicon wafer has been improved after introducing a new method in this paper. Small amount of surfactant along with KOH-IPA solution and curtailing saw damage removal step created better textural result than conventional texturization method. Optimize etching solution exhibited excellent anisotropic etching which eventually paved to improve solar cell characteristics than conventional surface texturing.

About $15 \%$ efficiency is found for conventional texturization in diamond cut wafers while above $19 \%$ efficiency was found for our proposed method. Batch process compatibility has been studied using stainless steel container instead of commercially available borosil glass bath. Keywords: diamond cut mono-crystalline silicon; KOH-IPA-NaOCL texturing; reflectivity.
\end{abstract}

Introduction: Recently the PV industry is greatly highlighting diamond wire saw (DWS) silicon wafer, because of the low kerf loss, high throughput, low production cost compared to the slurry wire saw (SWS) wafer [1]. Moreover, recent wafer technological trends are mainly emphasizing thinning wafer mechanisms because of low production cost and saving of material [2]. The sawing technique makes the DWS wafer much thinner compared to the normal SWS wafer [3]. These features undoubtedly put forward the DWS technology from SWS technology. Despite several advantageous features, DWS wafers have a structural deformity in the presence of saw marks and hard pits all over the surface [4]. Moreover, due to high dicing speed, the damaged layer is abundant in 10-20 nm amorphous silicon [4]. These damaged layers result in nonuniform surfaces and decimate the optical confinement within the entire bulk silicon followed by the reduction of ultimate solar cell conversion efficiency. Solar cell efficiency enhancement technique is based on the reduction of two losses; optical loss and electrical loss [5]. Normal 
mono $\mathrm{C}$-Si silicon wafer shows $40 \%$ reflection loss, which is not adequate for achieving highefficiency solar cell, so to enhance the optical confinement by reducing the enormous amount of reflectance, textured silicon surfaces are necessary[5]. The resulting textured pyramidal surface reduces reflectance by "double bounce effect" causing the enhancement of the overall conversion efficiency in the solar cell [3]. The presence of deep saw marks with an amorphous silicon layer on the surface of the DWS wafer does not allow the consecutive steps followed in the SWS wafer [3]. In the case of DWS wafer when the saw damage has been removed by $\mathrm{NaOH}$ followed by texturization, we see a non-uniform and degraded surface. Unlike the SWS wafer, the saw marks are thereafter the saw damage removal step. Conclusively the polishing nature and deep saw cut off the DWS wafers are one of the major drawbacks to achieve well-defined texturization [6]. There is very limited research work that has been reported to achieve successful texturization in diamond cut monocrystalline silicon wafer. Marcus Lippold (2014) has mentioned diamond wire saw marks removal with texturization by $\mathrm{HF}-\mathrm{HNO} 3-\mathrm{H} 2 \mathrm{SO} 4$ mixtures and found reflectance around 19\% [7]. Kexun Chen (2015) has reported surface polishing in diamond cut by TMAH solution. Texturization was done by commercial textured solution and eventually, $13 \%$ reflectance was found [8]. The alkaline textured solution was used by Prabir Kanti Basu et.al (2018). Here SDR step was carried out by $\mathrm{KOH}-\mathrm{NaOCl}$ solution heated at $80^{\circ} \mathrm{C}$, after which texturization was done by silicate-based low IPA texturing method. Reflectance was $12-13 \%$ for $15-20$ min etching [3].

This work targets to fabricate a novel industrially feasible texturization method in DWS wafer. Betterment of optical confinement with a cost-effective simple method is taken under consideration. To achieve our goal in this study the DWS wafers are texturized without SDR step because saw marks cannot be removed properly in this type of wafer due to high saw depth. These saw depth restrains the pyramidal etching. Alternatively, if the surface oxidation is enhanced in that way, all the pits and saw lines are oxidized uniformly, then pyramidal etching will be the same all over the surface. Here the texturization has been done by conventional $\mathrm{KOH}$, IPA solutions with one additive constituent $\mathrm{NaClO}$. $\mathrm{NaClO}$ helps to remove the impurities not only; it also enhances the wettability of the surface. It acts as a strong oxidizing agent [9], helping to produce silicon oxide and $\mathrm{H}_{2} \mathrm{O}$, whereas conventional SWS texturization results in the formation of an $\mathrm{H} 2$ bubble which restricts the reaction and growth rate. The experiment is carried out in a batch sequence over a large area $(158.75 \mathrm{~mm} \times 158.75 \mathrm{~mm})$ with 20 samples in each batch. The standard laboratory equipment for texturization of large-area sample needs a borosil glass container which is costly and difficult to obtain. So the experiment in large-area silicon is performed in thick gauge superior quality (grade 316) stainless steel containers procured from a stationery shop.

The standardization of the container has been approved by testing the corrosiveness with texture solution, capabilities of withstanding heat, and uniformity of heat scattering. This novel texturization method with innovative laboratory equipment allows the formation of a uniform pyramidal surface with solar weighted average reflectance (SWAR) of 9.88\%. Consistency and uniformity of texturization with successive batches have been tasted with different 
characterization tools. A single time etching solution allows eight successive batches for four days with the remarkable optical performance. All these features are indicating the method as industry-friendly and highly productive technology with cost-effectiveness.

\section{Experimental Details:}

\subsection{Texturization}

In this present work industrial graded $\mathrm{N}$ type, $\{100\}$ orientation, $\sim 2 \Omega$-cm resistivity DWS CZ wafers with size $78 \mathrm{~mm} \times 8 \mathrm{~mm}$ and $158.75 \mathrm{~mm} \times 158.75 \mathrm{~mm}$ are considered. Here pre-cleaning and SDR processes are excluded. Single Teflon stacks with 20 silicon wafers are directly transferred to a texturization bath with $2 \% \mathrm{KOH}, 6.5 \%$ IPA and $0.15 \% \mathrm{NaClO}$ in aqueous solution at $85^{\circ} \mathrm{C}$. The Teflon stack is indigenously manufactured in our laboratory. IPA and $\mathrm{NaClO}$ are added after reaching the temperature of $\mathrm{KOH}$ aqueous solution at $85^{\circ} \mathrm{C}$. It is very necessary to stir the entire solution for $1 \mathrm{~min}$ after adding all the ingredients. The texturization process time is varied between 45-55min. The experiment is performed in industrial feasible method so batch processing is mandatory. In single reaction solution eight consecutive batches are run. To maintain solution consistency after each batch one fourth of initial percentage of IPA and $\mathrm{NaClO}$ are added while $10 \%$ of initial $\mathrm{KOH}$ amount are mixed once after every two batches. After texturization the samples are rinsed in DI water and finally oxide free hydrophobic surfaces are found by dipping in a 7\% $\mathrm{HF}$ solution.

Texturization is mainly a two steps process: oxidation and dissolution [10]. In anisotropic texturization $\mathrm{KOH}$ is a well-known etchant for monocrystalline silicon and IPA enhances the wettability of the silicon surface. Here $\mathrm{NaClO}$ acts as a strong oxidizing agent. It helps to oxidize the surface of the wafer by forming $\mathrm{SiO} 2$ [10]. This $\mathrm{SiO} 2$ adds an oxygen ion from $\mathrm{KOH}$ and form SiO32- and water. In SWS conventional texturization, no oxidizing agent is used, so in reaction of $\mathrm{KOH}$ with $\mathrm{Si}$ make soluble $\mathrm{Si}(\mathrm{OH}) 4$ with extra $\mathrm{H} 2$ gas. This $\mathrm{H} 2$ in bubble form agglomerates on the silicon surface prohibiting the reaction with $\mathrm{KOH}$.

$\mathrm{NaCLO}=\mathrm{Na}^{+}+\mathrm{ClO}^{-}$

$\mathrm{CLO}^{-}+\mathrm{H}_{2} \mathrm{O}=\mathrm{HCLO}+\mathrm{OH}^{-}$

$\mathrm{Si}+\mathrm{CLO}^{-}=\mathrm{SiO}_{2}+2 \mathrm{CL}^{-}$

$\mathrm{KOH}=\mathrm{K}^{+}+\mathrm{OH}^{-}$.

$\mathrm{SiO}_{2}+2 \mathrm{OH}^{-}=\mathrm{SiO}_{3}{ }^{2-}+\mathrm{H}_{2} \mathrm{O}$

Here IPA helps to remove the bubble from the surface but high amount of IPA inhibits the reaction resulting decay of growth rate. $\mathrm{NaClO}$ also exaggerates the wettability of wafer and acts as cleaning surfactant which brings in uniformity of pyramid formation. Optimization of chemical ratio is significant here as large amount of $\mathrm{NaClO}$ can reduce the etching rate resulting in improper shape of pyramids whereas high concentration of $\mathrm{KOH}$ can enhance the etching rate. As a result, thinning of the wafer can happen; this is not perfect for further solar cell fabrication process.

\subsection{Solar cell fabrication}

In this experiment we have used conventional boron diffusion by $\mathrm{BBr}_{3}$ source in open tube furnace at $945^{\circ} \mathrm{C}$ for $15 \mathrm{~min}$ to form $\mathrm{p}^{+}$emitter surface. The rear sides of the wafers were diffused 
by $\mathrm{POCL}_{3}$ source at $900{ }^{\circ} \mathrm{C}$ for $20 \mathrm{~min}$ to form $\mathrm{n}+$ region. BSG (boro silicate glass) and PSG (phosphor silicate glass) are removed after corresponding diffusion step. Sheet resistance has been studied for conventional and proposed texturized samples after diffusion step. $\mathrm{Al}_{2} \mathrm{O}_{3}$ $(10 \mathrm{~nm})$ front surface passivation and application of $\mathrm{SiNx}(80 \mathrm{~nm})$ anti-reflection coating by PECVD are done on each sample. Metallization was done in all samples by standard screen printing followed by baking and co-firing at $900{ }^{\circ} \mathrm{C}$. Optical and electrical characterizations of conventional and proposed textured silicon solar cell were tasted.

\section{Results and discussions:}

Our texturization reaction is a one step process so the necessary laboratory equipment is borosil glass beaker to restrain contamination but borosil glass beaker for large area $(158.75 \mathrm{~mm} \times 158.75 \mathrm{~mm})$ samples is costly, rare and difficult to handle. So alternatively we manage the texturization bath, replacing with superior quality stainless steel container (fig.1). To see the effect in the chemical ambience, the container is kept aside for two nights with the texturization solutions. There is no effect found in the container surface. It also successfully withstands heat with uniform spreading of temperature.

\subsection{FTIR analysis:}

To reveal the effect of steel container and the use of NaOCL on the surface of the wafer FTIR analysis have been performed in fig. 1b.The transmission peak at $2350 \mathrm{~cm}^{-1}$ is the $\mathrm{CO}_{2}$ peak [11]. The peak at $1103 \mathrm{~cm}^{-1}$ is due to the presence of Si-O bond [12].There are two peaks are attributed at $873 \mathrm{~cm}^{-1}$ and $733 \mathrm{~cm}^{-1}$. These bands are appearing for C-H stretching [13]. It is clear from the graph that there is no contamination. Only oxide bond is there.
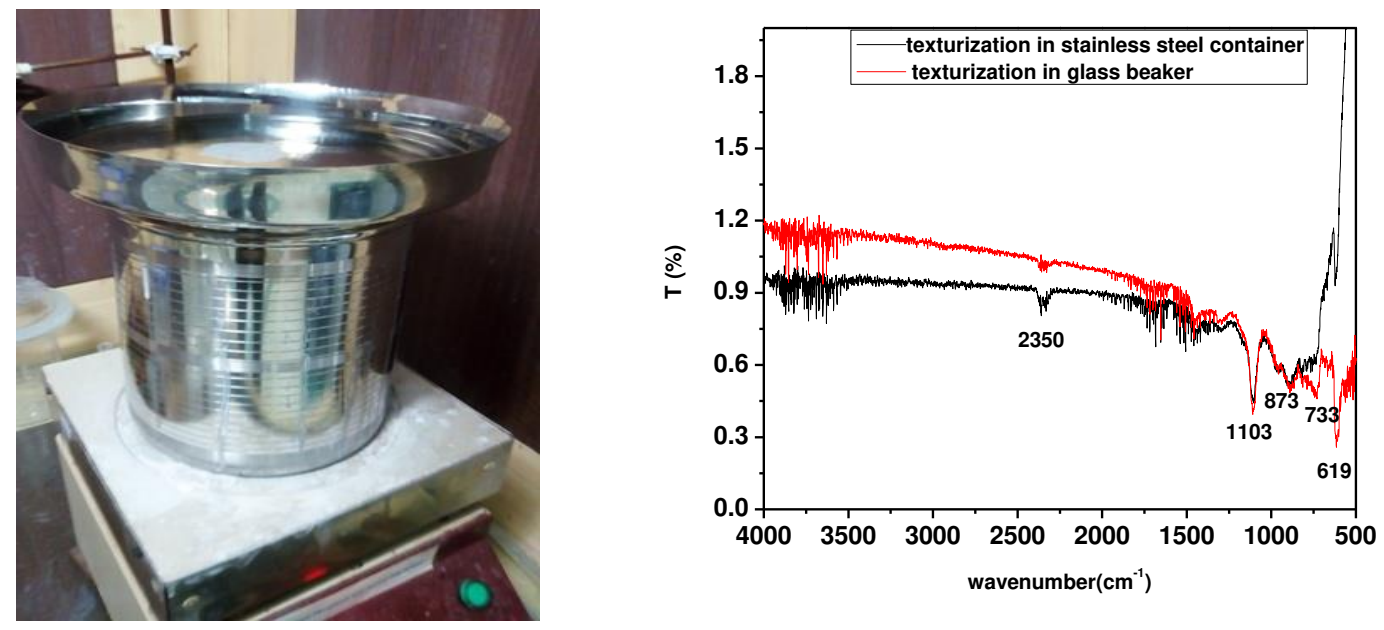

Fig 1.a. Steel can for texturization of wafers $(76.2 \mathrm{~mm} \times 76.2 \mathrm{~mm})$, b.FTIR analysis of diamond cut textured $\mathrm{n}$ type wafer in stainless steel and glass beaker

\subsection{Surface analysis of DWS wafer by FESEM study:}

In (100) plane of silicon there are only two back bonds attaching two surface silicon atoms while (111) planes possess three back bonds with two surface silicon atoms (fig.2). During 
texturization it is much easier to etch (100) plane instead of (111) plane [14]. So in anisotropic texturization pyramidal structure is formed in (111) facets with $54.7^{\circ}$ intersection angle between (100) and (111) plane [15].

Fig3 shows FESEM analysis of textured silicon surface in batch 1 to 8 . It demonstrates surface quality of pyramidal texturization of DWS wafer for different batches in single texturization solution. In Fig. 3a to $3 \mathrm{f}$ most of the pyramid heights are within $3-5 \mu \mathrm{m}$ while in $3 \mathrm{~g}$ and $3 \mathrm{~h}$ pyramidal structures are not well defined; some additional growths are there on the pyramidal wall.
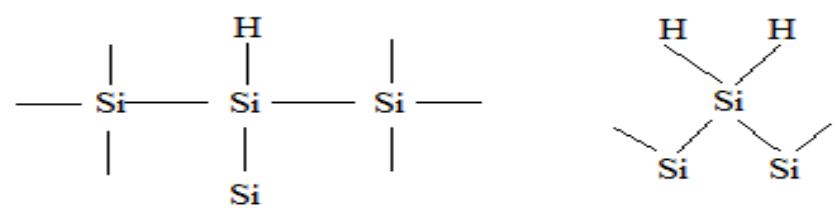

Fig 2. Bond structure of silicon(100) and (111) plane

The image depicts that the surface is plenty of uniform pyramidal structure with no saw marks or defects. It clearly indicates the reaction solution consistency maintains up-to six batches. From seventh batch it slightly starts to degrade and in batch 8 improper pyramidal shapes has formed, indicating poor texturization.
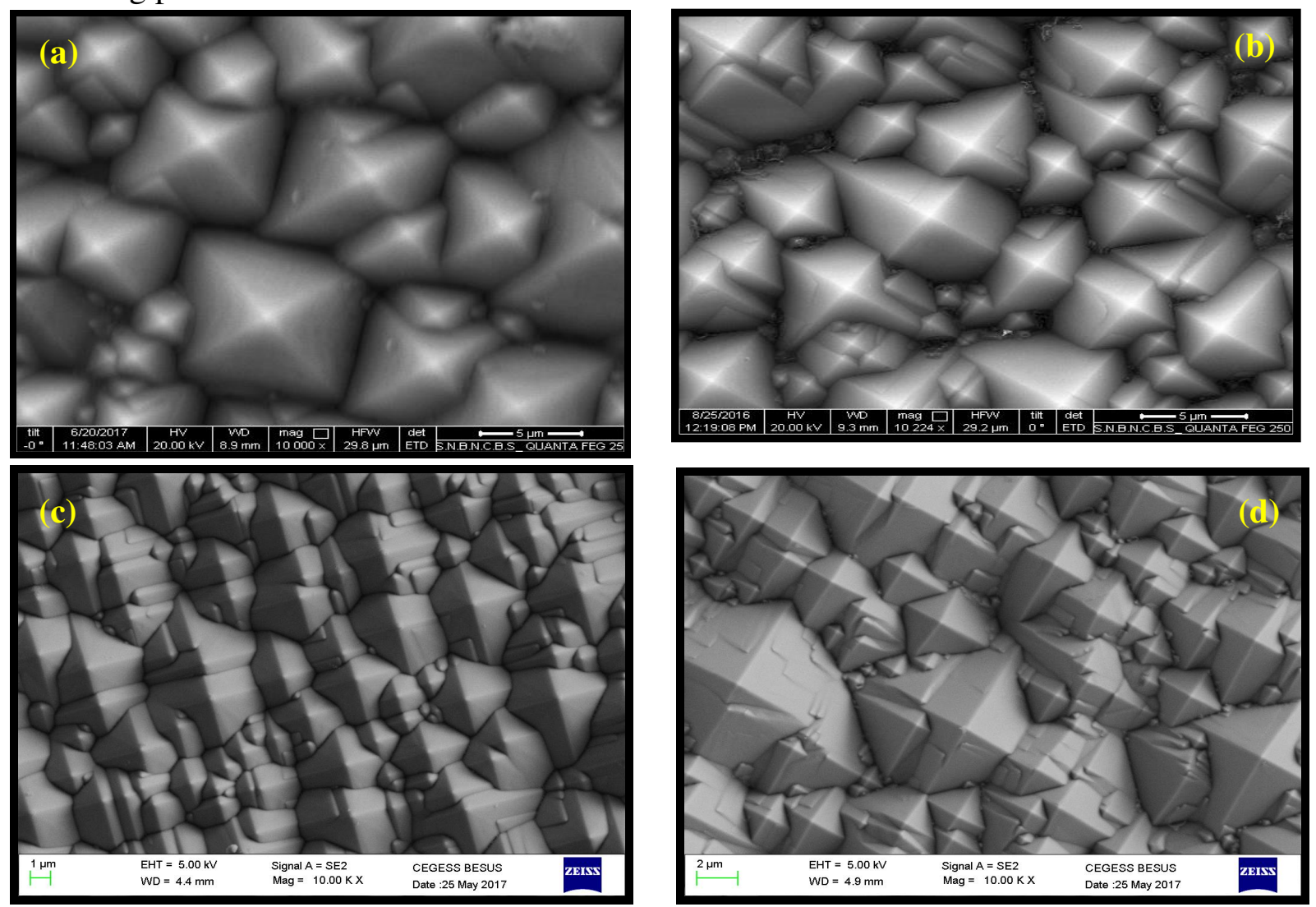

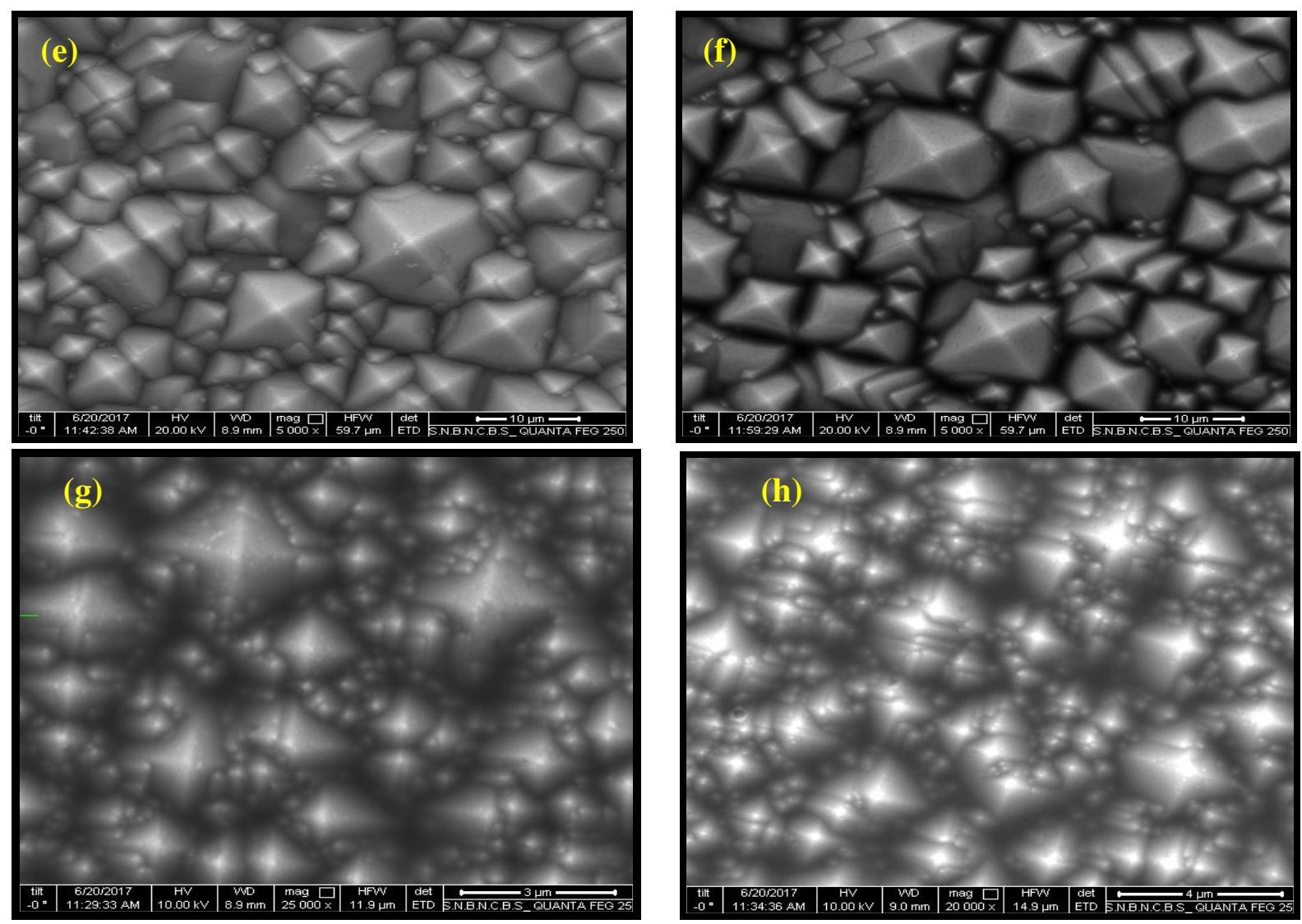

Fig.3 FESEM image of DWS textured sample in (a) batch 1, (b) batch 2, (c) batch 3, (d) batch 4, (e) batch 5, (f) batch $6,(\mathrm{~g})$ batch 7 and (h) batch 8 .

In industrial scale if a single solution can manage continuous reaction for a few days it becomes much cost effective so aging study of the solution is necessary. This feature is measured by keeping the solution for three days and in each day two batches texturization are performed. Fig.4 indicates FESEM analysis of each day first batch textured samples and this study successfully emphasizes non degraded surface. Pyramidal heights are within $4-5 \mu \mathrm{m}$. No saw marks are seen.
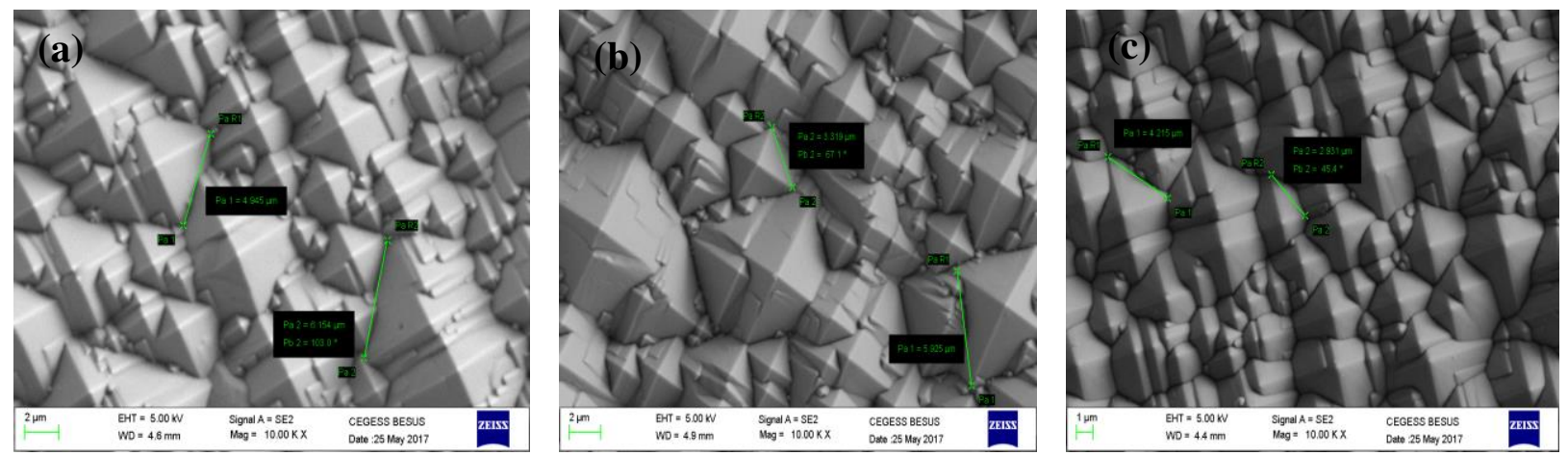

Fig.4 FESEM image of DWS textured sample in (a) day 1 batch 1, (b) day 2 batch 1, (c) batch 3 batch 1 .

Betterment of performance by using $\mathrm{NaOCl}$ without $\mathrm{SDR}$ is validated by figure. 5. Here comparison between two methods is carried out simultaneously by FESEM micrograph. Texturizations of DWS samples are done by two methods; one is SDR followed by commercial 
texturization and another one is our proposed novel method. Highly disordered growth with totally improper pyramidal shape is observed in figure $5 \mathrm{~b}$ while ordered and dense uniform pyramidal growth (fig.5a) on all over the surface has been found by our new texturization solution.
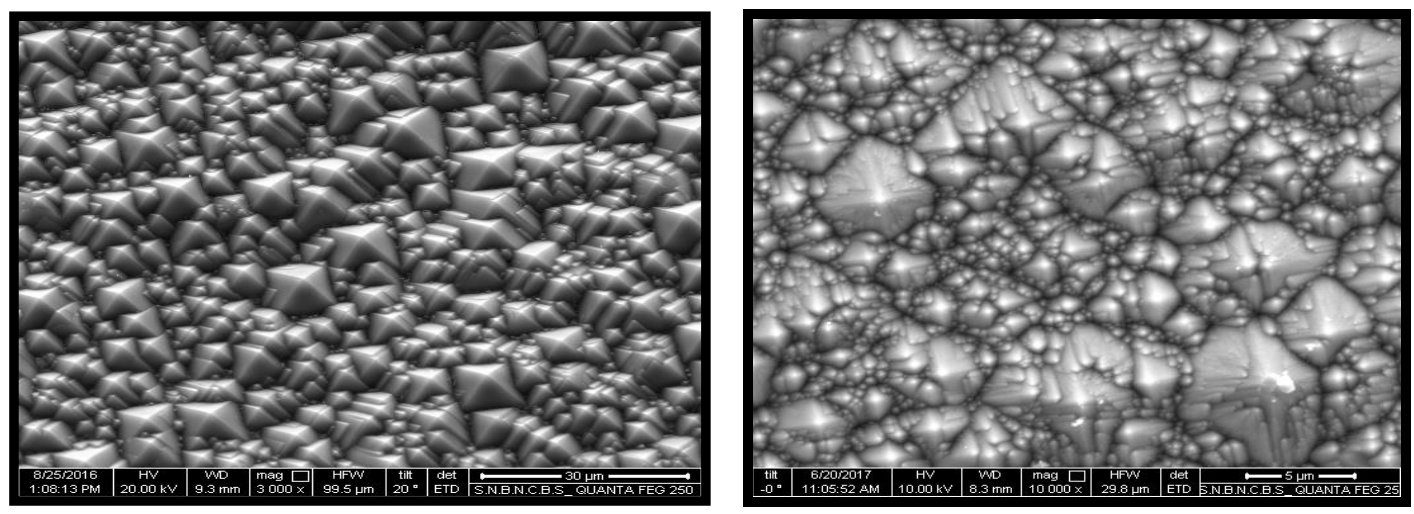

Fig.5 FESEM image of DWS textured sample by (a) our proposed method, (b) conventional texrization with SDR.

\section{iii. Reflection analysis of DWS wafer:}

Texturization plays a major role to amplify the light confinement within the substrate. The light trapping theory is described by phenomenon of multiple reflections although the theory is complex one. To avoid complication classic molecular dynamics (MD) model is applied [16]. When a light photon strikes the substrate with an angle $\theta$, the photon should be attracted by the silicon atom but a parallel contrasting force drives the photon towards other direction if the photon crosses the boundary limit of silicon atomic attraction force field.

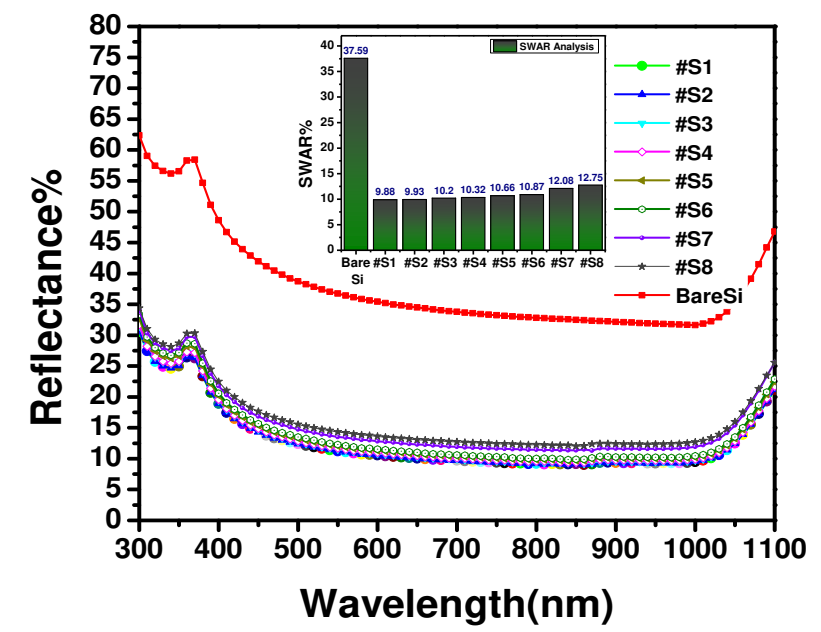

Fig.6 Variation of reflectance and SWAR analysis for DWS textured wafer for different batch; \#S1=batch1 sample, \#S2=batch2 sample, \#S3=batch3 sample, \#S4=batch4 sample, \#S5=batch5 sample, \#S5=batch1 sample, \#S6=batch6 sample, \#S7=batch7 sample and \#S8=batch8 sample. 
This photon is then stroke to another pyramidal wall and the same phenomenon repeats. In like manner the photon gets enter into the substrate. It has already been reported that $30 \%$ normal incident light can hit three times of randomly grown upright pyramidal wall [17]. Amount of light which is transmitted are absorbed in the wafer. Few amount of light in visible wavelength is lost from the rear surface of the wafer. These photons of light generate electron hole pair and thus current is generated in solar cell. The reflection analysis of our sample is tested by UVVIS-NIR spectrophotometer (Solid-Spec 3700, Shimadzu) from the wavelength 300 to $1100 \mathrm{~nm}$. Above this wavelength region photon energy becomes less than silicon band gap energy so it cannot generate electron hole pair. So the desired photon energy should be within the mentioned wavelength region. Reflection graph clearly demonstrates the excess amount of reflection reduction by textured silicon surface than bare as cut silicon. This is happened due to multiple reflections phenomenon. To specify the exact amount of reflection, SWAR (solar weighted average reflectance) value has been calculated.

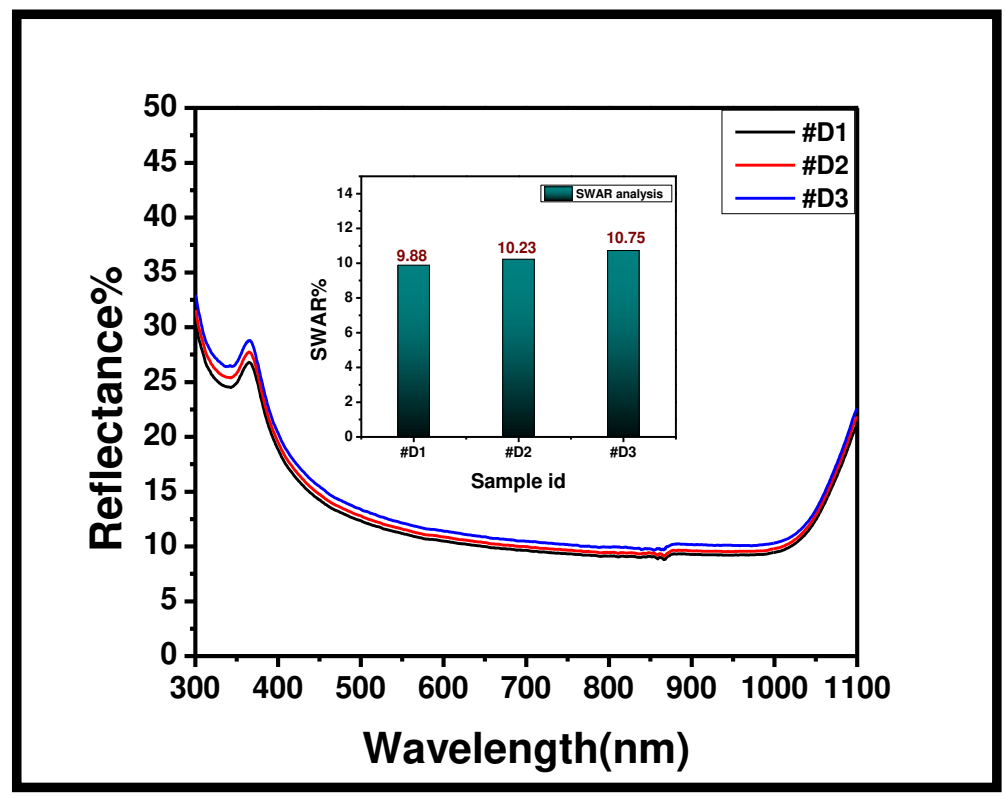

Fig.7 Variation of reflectance and SWAR analysis for DWS textured wafer for different day batch;\#D1= batch1 day1, ;\#D2= batch1 day2, ;\#D3= batch1 day3.

$\mathrm{SWAR}=\frac{\sum_{300}^{1100} R_{\lambda} I_{\lambda} d \lambda}{\sum_{300}^{1100} I_{\lambda} d \lambda}$, where $\mathrm{R}_{\lambda}$ is the reflectance and $\mathrm{I}_{\lambda}$ is the solar irradiance over $\mathrm{d} \lambda$ wavelength. It defines the average reflectance for solar irradiance over desired wavelength region.

\section{iv. Reflection analysis of different batch sample}


Textured silicon SWAR value starts from $9.88 \%$ which is $26 \%$ lower than as-cut silicon (fig.7). Silicon is incapable to absorb UV lights properly so humps are seen near 300-400 nm range above which the reflectance reduces over broadband spectral range.

The advancement of batch number reduces reflectance slowly. In batch 1 sample \#S1 shows minimum reflectance as the chemical constituents becomes perfect in this condition. As mentioned earlier after completion of each batch some chemical ingredients have been added to withhold the consistency of initial solution. Up-to six batch (sample \#S1 to \#S6) the reflection is within $10-11 \%$, which is standard for industrial production but after six batches the reflection starts to increase. \#S7 and \#S8 shows reflectance above 12\%. This indicates the solution capability degrades.

\section{v. Reflection analysis of different sample by aging of chemical solution}

To define chemical consistency of reacting solution another experiment has been done. We have considered three days and each day two batches have been completed. After completion of each two batches the solution has been kept overnight and again starts the reaction likewise. $\mathrm{KOH}$, IPA and $\mathrm{NaOCl}$ have been added by same as mentioned during batch sequence. Reflection is measured for sample of $1^{\text {st }}$ run of each day. It is cleared from the graph that the solution behaves same as previously; no degradation occurs. The reflection is within $9-10 \%$ which same as before (figure 8). This experiment is significant to analyze the low fabrication cost of DWS wafer texturization in our preferred way.

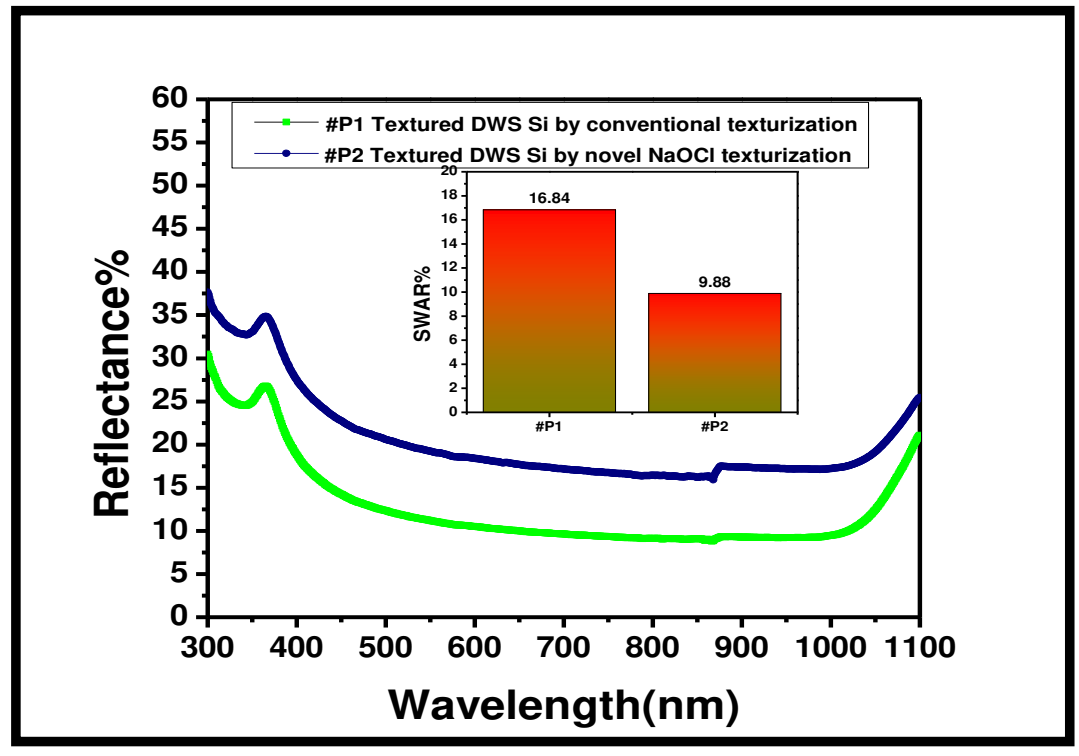

Fig.8. Comparison of reflection analysis between textured DWS silicon by conventional SWS texturization solution and our proposed novel solution.

vi. Comparison between texturization by our proposed method and SWS conventional texturization by reflection 
Significant difference is observed between texturization of DWS wafer by our preferred method and conventional SWS texturization method. Although from figure5 it is cleared that texturization of DWS wafer by conventional SWS texturization method produces uneven pyramid with overlapped and unorganized growth, it becomes much assured by reflectance graph (fig.8).

The value of SWAR of DWS wafer by SWS conventional texturization method is above $16 \%$ while our proposed method diminishes the reflectance about $9 \%$ which is much better undeniably.

\section{vii. Consistency and Uniformity of textured DWS wafer}

Consistency and uniformity of reflection of textured wafer over large area $(158.7 \mathrm{~mm} \times 158.7 \mathrm{~mm})$ is significant to establish the technology in industrial scale. To validate our novel method for large area texturization, 10 samples are picked up from each batch and measure reflectance. Figure 9a shows histogram analysis of each batch constituency and with the advancement of batch number SWAR value changes same for each sample. It manifests the ideality of batch process in our solution. For large wafer uniform surface texturization has been approved by next result. Here one sample is chosen from each batch and measure the reflectance from ten different position of the wafer.
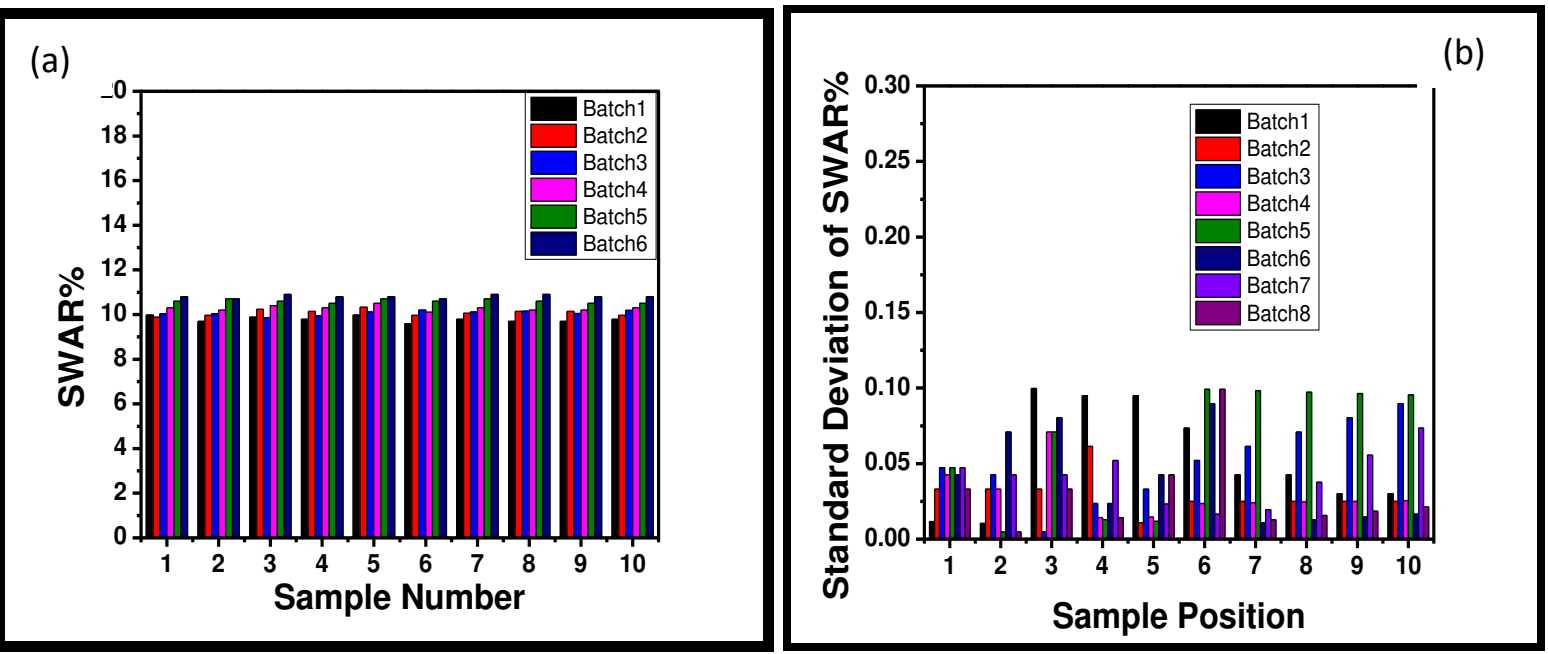

Fig.9 (a) Consistency and (b) uniformity taste of each batch process of texturization

From reflectance graph SWAR value has evaluated and from this standard deviation is calculated. Graph 9b shows standard deviation of SWAR\% with change in different position of the wafer and very non-significant deviation of reflectance occurs over change in measurement position of textured wafer. This data is also significant to validate our proposed solution for large area wafer texturization as industrially viable technology.

viii. 3D AFM image analysis 
Surface analysis is more clearly understood by Atomic Force Microscopic (AFM) study. Typical AFM picture of batch 1,3,6 and 7 measure the consistency and stability of reaction by studying pyramidal height in 3D orientation.
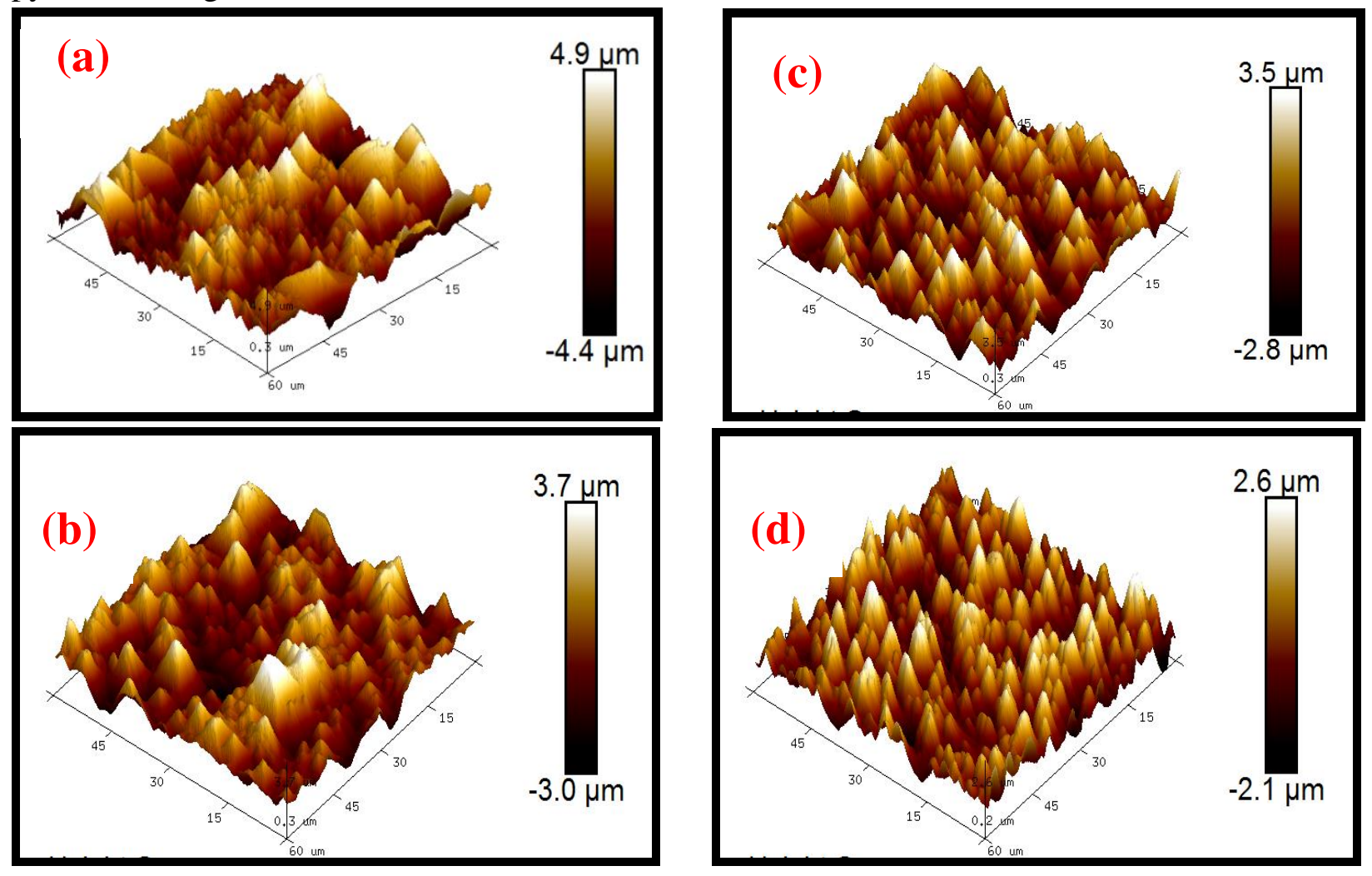

Fig.10 Typical AFM analysis of DWS textured samples (a) batch1 (b) batch3 (c) batch6 (d) batch7 As the variation of reflectance and surface pyramidal structure (fig.3 and fig.6) is not considerable in every batch so AFM 3D image analysis is given for significant batches only where the changes begin. In first batch maximum height of the pyramid is $5 \mu \mathrm{m}$. From the $3 \mathrm{~d}$ height distribution image of textured surface in fig 10a it is cleared, maximum pyramid heights are within $3-5 \mu \mathrm{m}$ and with the sequential proceeding of batch number pyramid heights decreases. Pyramid heights are maintained between $3.5-5 \mu \mathrm{m}$ from batch 1 to batch 6 with uniform pyramidal structure. In fig $10 \mathrm{~b}$ and batch 7 the heights of the pyramids diminish to $1.9 \mu \mathrm{m}$.

This is due to slight deterioration of texture solution. Although reaction ingredients are added in each batch but the change in molarity of the solution alters reaction rate; thereby the size of the textured pyramids reduces. This manifests our novel textured solution can texturized up to six successive batches.

\section{ix. Depth analysis by AFM image of different batch sample:}

The histogram and depth analysis of textured silicon surface provides the information about the heights of the pyramids and the number of pyramids with that height. In this case depth of the pyramids is changed with batch sequence (fig.11). 

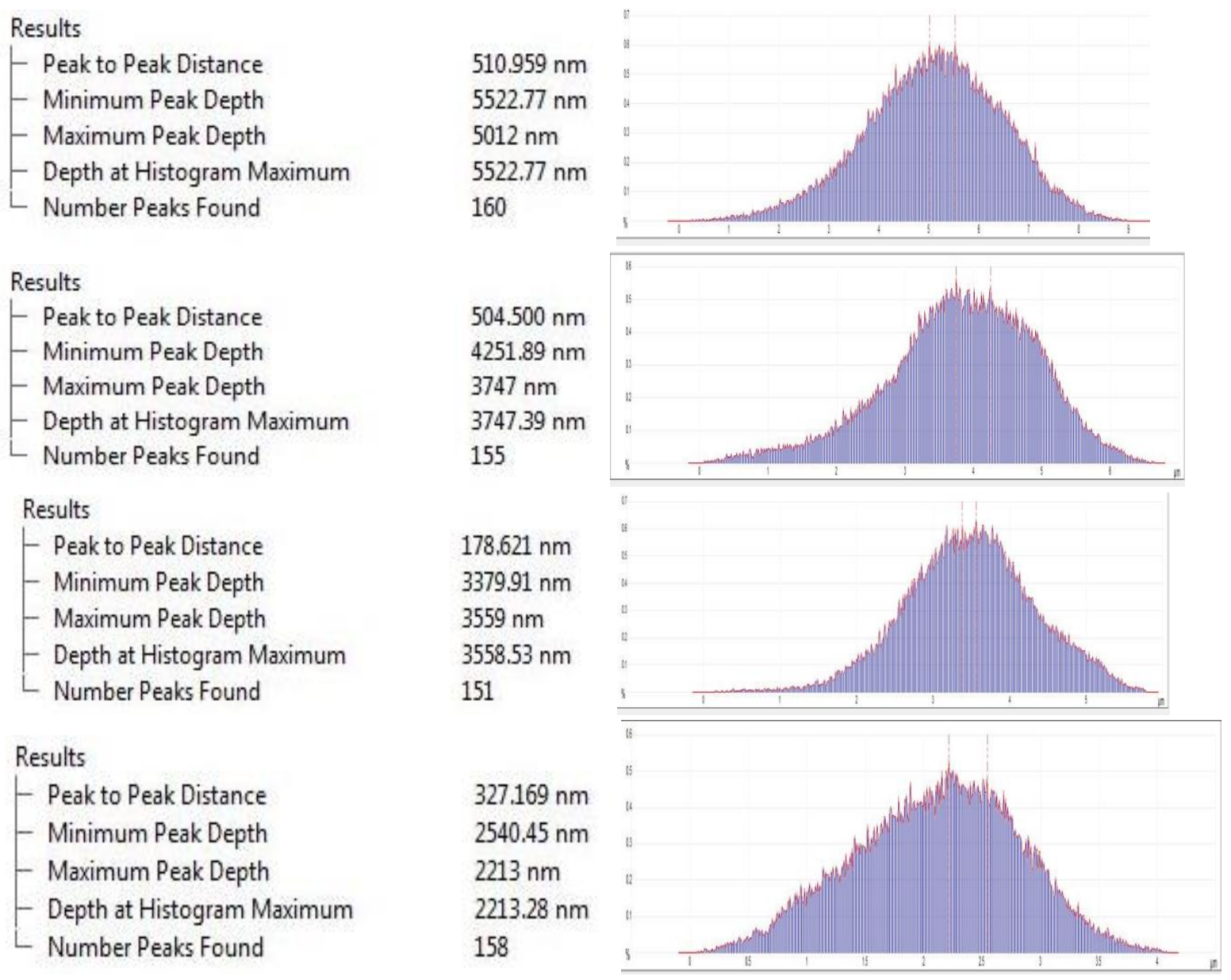

Fig 11 Depth analysis of DWS textured samples (a) batch1 (b) batch3 (c) batch6 (d) batch7

From maximum and minimum peak depth, the distribution of the pyramids can well be defined. The total scanning area is $900 \mu \mathrm{m}^{2}$. In batch 1 there are 160 picks with $5 \mu \mathrm{m}$ pyramidal height while in batch 3 and batch 6 the heights reduces to $3.5 \mu \mathrm{m}$. Numbers of peaks are nearly same. In batch 7 the height becomes $2.2 \mu \mathrm{m}$ however the number of peaks are same. The heights are reducing due to concentration of ingredients changing. All these studies are mentioning uniform structural distribution. Very few micrometers are left within with different pyramidal heights.

\section{$x$. Surface Roughness analysis by AFM image of different batch sample}

Surface roughness is important here to study the surface quality of textured silicon(fig.12). If more pyramids with particular heights are there, surface roughness will usually be higher. In this analysis maximum roughness is found in batch 1 as in first batch the consistency and proportion of the textured solution ingredients are exact. In batch 3 and 6 surface roughness is nearly same. There are lots of pyramids with heights between 3.5-4 $\mu \mathrm{m}$ but as the batch number proceeds chemical solution gets changed its proportions and thus the heights and distributions of the long heighted pyramids reduces. So the surface roughness decreases consistently. Minimum roughness is thus found for batch 7 . 


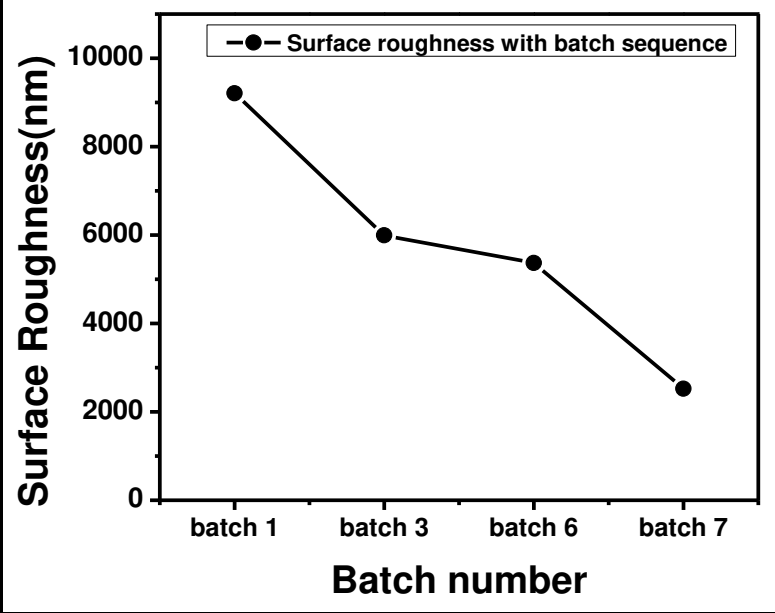

Fig.12 Typical Surface roughness study of DWS textured pyramids with the change in batch sequence xi. Pyramidal uniformity check by AFM image analysis
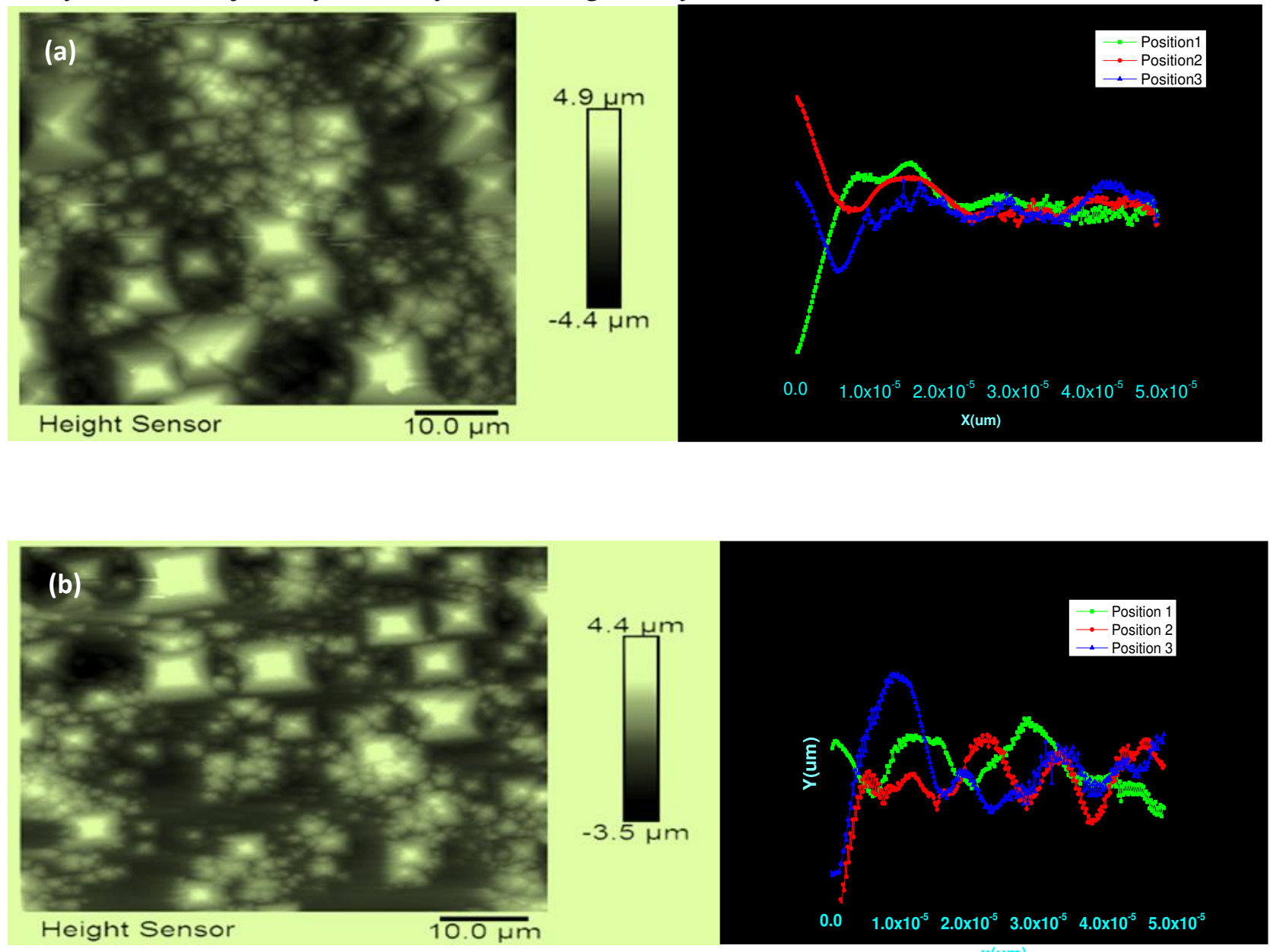

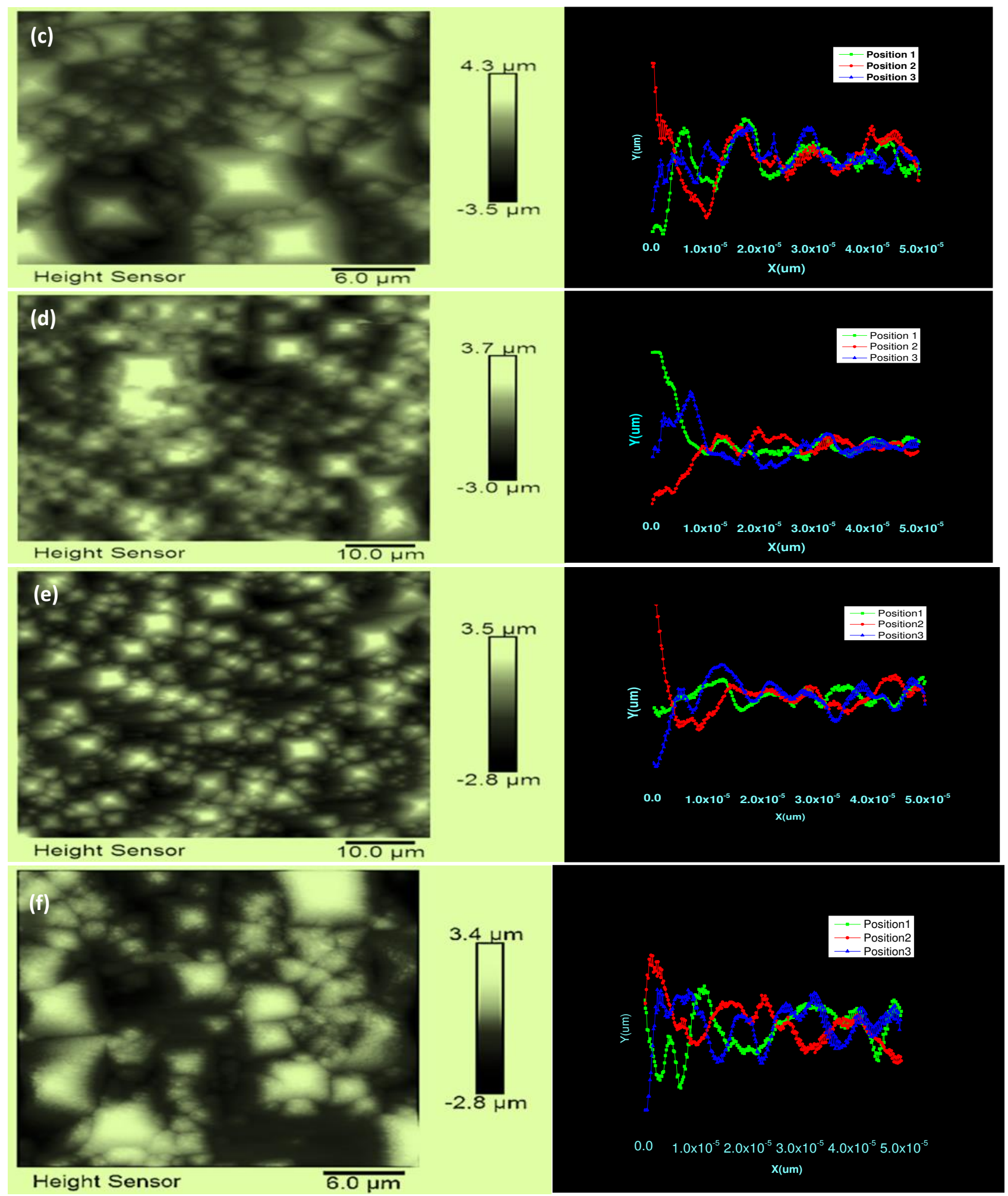

$0.0 \quad 1.0 \times 10^{-5} 2.0 \times 10^{-5} 3.0 \times 10^{-5} 4.0 \times 10^{-5} 5.0 \times 10^{-5}$ $\mathrm{X}(\mathrm{um})$ 


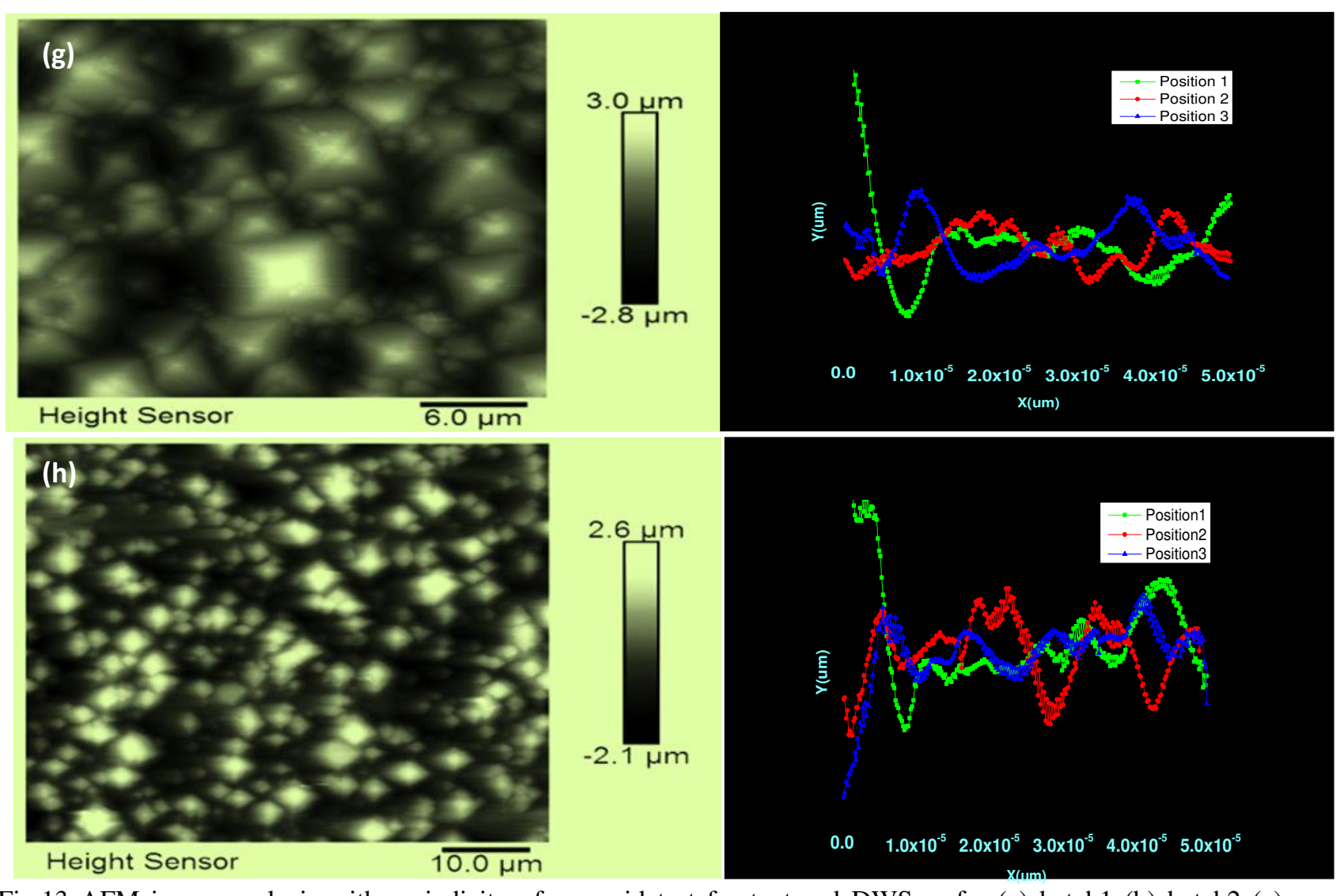

Fig.13 AFM image analysis with periodicity of pyramid test for textured DWS wafer (a) batch1 (b) batch2 (c) batch3 (d) batch4 (e) batch5 (f) batch6 (g) batch7 (h) batch8.

To analyze AFM data more precisely, different types of simulation has been done (fig.13). Gwyddion microscopic data processing software is used for this purpose. 2D AFM image has been extracted by profile tool. It provides variation of surface roughness in 1D wave pattern. Three different position lines are chosen over which the roughness has been extracted. From figure13a it is clear that the variations marked by green, blue and red lines for three individual positions are almost same. Here the amplitudes of all the three waves merge with each other which definitely ingrained the uniformly grown pyramidal structure. The peaks of the curves define the pyramidal peak.

The structure has been formed in same pattern over three lines. In figure little discrepancy occurs. Although the number of pyramidal peaks is same but they are not grown parallel in a same way. In figure $13 b$ the waves are almost merged uniformly dense same sized pyramidal growth. Deviation occurs from batch 7 . The waves here are different amplitudes and they are not merged anyway. This measures the non-uniform growth pattern of pyramids. Progression of batch number slowly degrades the reaction solution by changing molar concentration of its ingredients. In batch 7 and 8 (fig.13f and fig.13g) the waves are differently spread with different amplitudes and frequencies. The maxima and minima are not merged which indicate nonuniformly grown pyramidal structure after batch6. 


\section{xii. Pyramidal tip inclination analysis}

Ideally textured pyramidal wall makes $54.7^{\circ}$ angles with base but the angle gets changed due to chemical degradations. This feature is calibrated by facet analysis. This analysis enables to study the local inclination of surface plane [17]. From facet analysis Cartesian and Polar coordinate values the tilting angle has been calculated. The variation of pyramidal tilting angle is calculated by the method. The inclination happens due to uneven and improper growth of pyramid.

It can be a reason if four base sides of a pyramid is not equilateral then the tip can be inclined over a particular angle.

With change in pyramidal tip inclination, incident light angle also changes and thus reflectance. The 3D graph analysis (fig.14) measures the angular variation with change in batch number. Figure 11 shows the screen shot image of simulation result for a typical AFM image. Different parameters are found with respect to different coordinate system. Here initial batch is considered reference with respect to which other batches are measured.

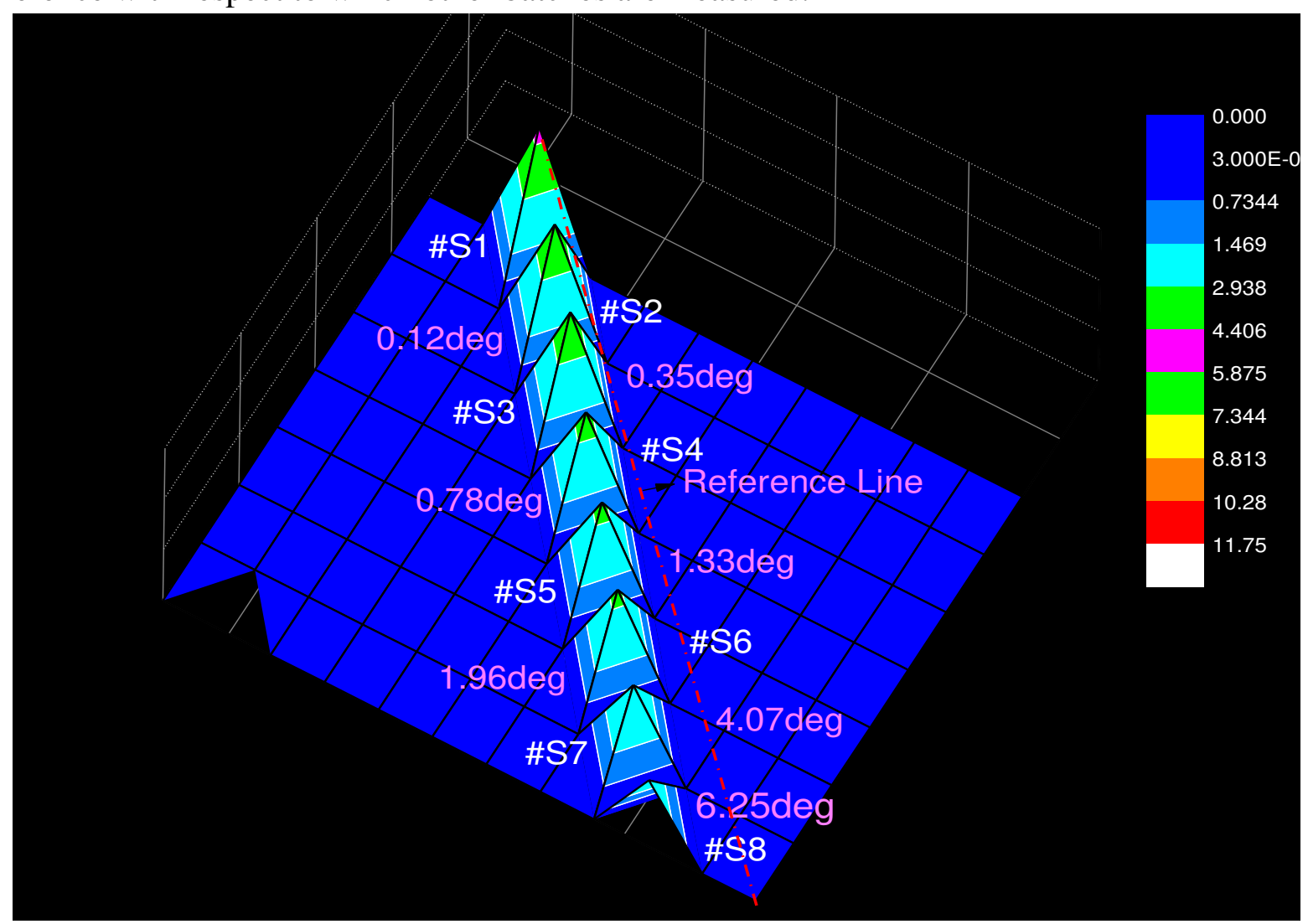

Fig.14 Pyramid tip inclination with advancement of batch

With change in height angular variation becomes significant after batch 6(\#S6). In $8^{\text {th }}$ \#S8) batch 6.25 degree pyramid tip inclination occurs and thus the light incident angle changes followed by reflection enhancement.

\section{xi. Solar cell characteristics and yield analysis:}

Diffusion in front and rear surface of the textured silicon showed different characteristics for our two adopted texturization methods. Surface uniformity played major role for betterment of diffusion. In $\mathrm{KOH}$ with saw damage removal texturization, surface uniformity was not 
satisfactory whereas texturization with our proposed method shows surface uniformity. After diffusion sheet resistance has been measured which defined the uniformity of diffusion. Figure 15 showed the sheet resistance of both types of texturization.
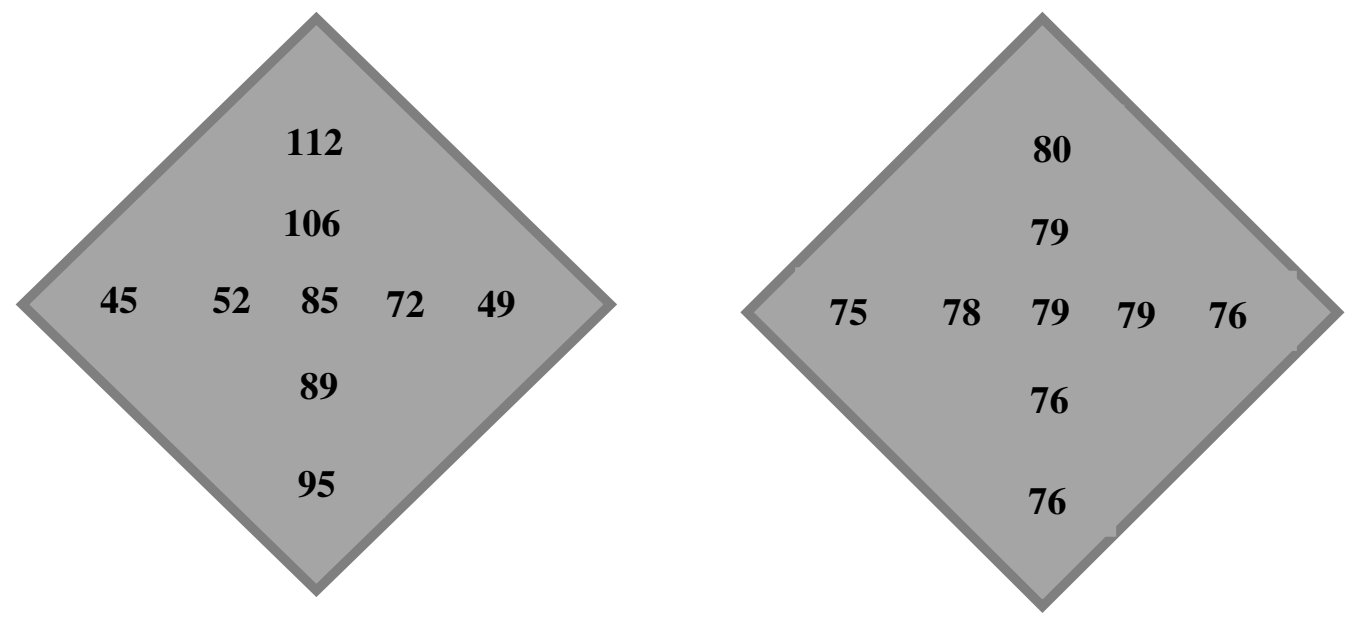

Fig. 15 Sheet resistance analysis in $(\Omega / \square)$ for texturization with (a) KOH with saw damage removal (b) KOH with $\mathrm{NaOCl}$ without saw damage removal.
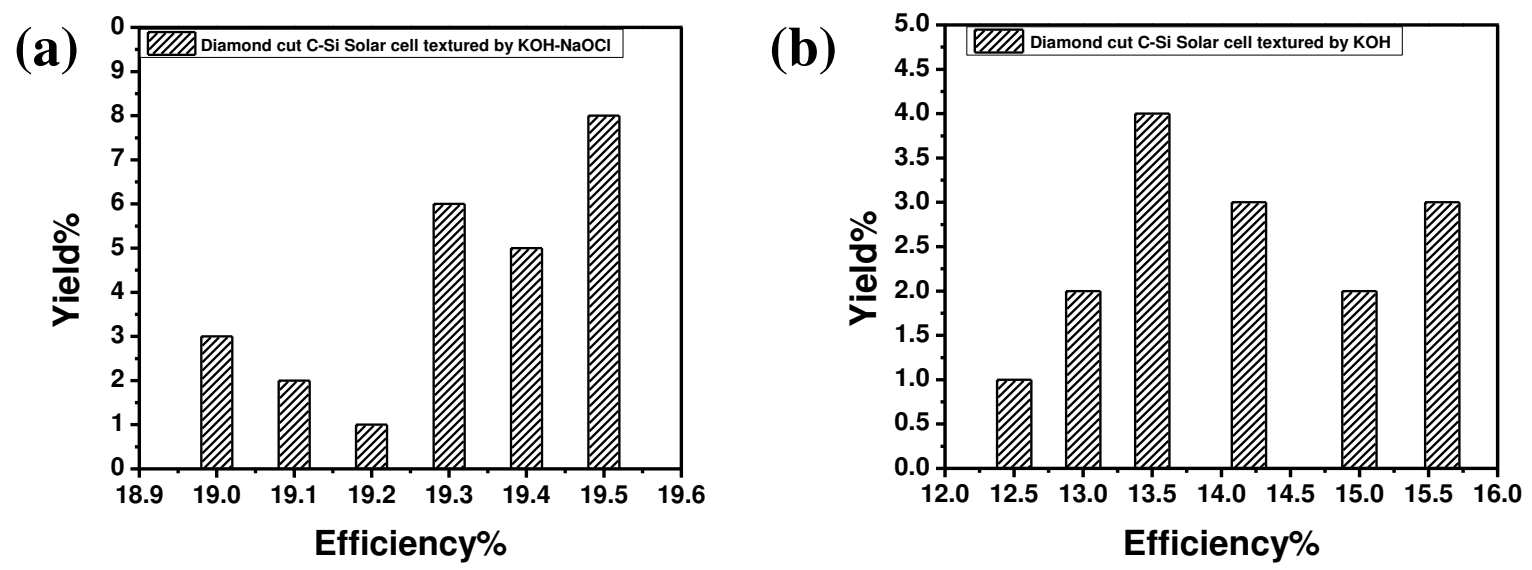

Fig.16 Variation of yield of efficiency for (a) diamond cut c-Si Solar cell textured by KOH-NaOCl without saw damage removal, (b) diamond cut c-Si Solar cell textured by $\mathrm{KOH}$ with saw damage removal.

Surface passivation with $\mathrm{Al}_{2} \mathrm{O}_{3}$ on front surface and $\mathrm{HfO}_{2}$ on rear surface was done by thermal ALD using Trimethylaluminum precursor (TMA) and Tetrakis (dimethylamino) hafnium (TDMAH) precursors. SiNx ARC was deposited by PECVD. Illuminated current-voltage characteristics of the finished diamond cut crystalline silicon cells with $\mathrm{KOH}-\mathrm{NaOCl}$ texturing and that with $\mathrm{KOH}$ solution were observed under AM 1.5 global spectrums in solar simulator. Overall efficiency is much higher in $\mathrm{KOH}-\mathrm{NaOCl}$ textured wafer than $\mathrm{KOH}$ textured. Low open circuit voltage and fill factor indicates higher leakage current in $\mathrm{KOH}$ textured silicon. Lower leakage current of $\mathrm{KOH}-\mathrm{NaOCl}$ textured silicon indicates uniform surface structure on all over 
the large area $(158.75 \mathrm{~mm} \times 158.75 \mathrm{~mm})$ of the wafer and also the reducing steps in saw mark region. Here we have achieved $72 \%$ yield in efficiency $19.2-19.5 \%$ for $\mathrm{KOH}-\mathrm{NaOCl}$ textured wafer as shown in fig. 15(a) whereas in conventional textured wafer it was not well defined (fig.15b). The efficiency varied for different wafers. This is because for texturization by $\mathrm{KOH}$ makes the surface of the wafer non-uniformly distributed pyramids leading to different surface structure at different position of the wafer.

Conclusion: Diamond wire saw (DWS) wafer is capturing attention of industrial solar cell technology due to its low kerf loss, high through-put, low production cost compared to SWS technology but deep saw marks with amorphous silicon layer of DWS wafer make difficulties in texturization. Conventional texturization by saw damage removal step is not the right way to form uniform pyramidal structure in DWS wafer. This work have proposed a cost effective industrially feasible texturization method for diamond wire saw(DWS) c-Si wafer. Our novel solution successfully eliminates the saw marks and defects from the surface and uniform pyramidal structure forms on all over the substrate surface. $\mathrm{NaClO}$ here acts as strong oxidizing agent helps to make silicon oxide so etching is uniform all over the surface. Laboratory footprint is made by industrially applicable method. Batch process compatibility has been studied by different types of surface characterization. A single solution can texturized six batches with consistently same reflection losses. Micro pyramidal structure is uniformly grown on large area $(158.75 \mathrm{~mm} \times 158.75 \mathrm{~mm})$ surface. Reflectance of DWS wafer by our proposed method is lower than conventional SWS textured silicon wafer. Simulation results also convey insignificant inclination of pyramidal tip, which definitely explains no degraded pyramidal pattern with advancement of batch number. This work makes a tremendous possibility to achieve high efficiency solar cell.

Acknowledgement: The authors are grateful to the SERI DST, Govt. of India for financial support for carrying out solar cell related research activity. The authors deeply acknowledge Meghnad Saha Institute of Technology, TIG provides the infrastructural support for carrying out research activity in this area. The authors are also grateful to CEGESS, IIEST for their valuable support and providing infrastructure to perform the experimental analysis.

\section{Availability of data and material: Not Applicable}

\section{Reference:}

[1]. Arkadeep Kumar and Shreyes N. Melkote, "Diamond Wire Sawing of Solar Silicon Wafers: A Sustainable Manufacturing Alternative to Loose Abrasive Slurry Sawing", 15th Global Conference on Sustainable Manufacturing, Procedia Manufacturing, vol-21,(2018),pp-549-566.

[2]. Science News, Massachusetts Institute of Technology, January 28, 2020.

[3]. Prabir Kanti Basu, Sreejith KP, Tarun S. Yadav, Anil Kottanthariyil, Ashok Kumar Sharma, "Novel lowcost alkaline texturing process for diamond-wire-sawn industrial monocrystalline silicon wafers", Solar Energy Materials and Solar Cells, Solar Cells, vol-185, (2018) pp-406-414.

[4]. Mauricio Ariasa, Mackarena Briceñoa, Aitor Marzob Antonio Záratea, "Optical and electrical properties of silicon solar cells by wet chemical etching", Journal of the Chilean Chemical Society, vol.64, 2019. 
[5]. Santo Martinuzzi, Abdelillah Slaoui, Jean-Paul Kleider, Mustapha Lemiti, Christian Trassy, Claude LevyClement, Sébastien Dubois, Remi Monna, Yves Veschetti, Isabelle Périchaud, Nam Le Quang,Jed Kraiem, "Silicon Solar Cells", Crystalline,2012 edition.

[6]. Srinivasamurthy Devayajanam, "Experimental and theoretical evaluation of in-depth damage distribution in sawn silicon wafers", New Jersey Institute of Technology,Winter 1-31-2016

[7]. Marcus Lippold, Florian Buchholz, Christoph Gondek, Florian Honeit, Eckard Wefringhaus, Edwin Kroke, "Texturing of SiC-slurry and diamond wire sawn silicon wafers by HF-HNO3-H2SO4 mixtures", Solar EnergyMaterials\&SolarCells, vol-127(2014)pp-104-110.

[8]. Kexun Chen, Yunyu Liu, Xusheng Wang, Lingjun Zhang, Xiaodong Su, "Novel texturing process for diamond-wire-sawn single-crystalline silicon solar cell”, Solar Energy Materials \& SolarCells, vol-133 (2015),pp-148-155.

[9]. Carlos Estrela; Cyntia R.A. Estrela; Eduardo Luis Barbin; Júlio César E. Spanó; Melissa A. Marchesan; Jesus D. Pécora, "Mechanism of action of sodium hypochlorite", Braz. Dent. J. vol.13 no.2 Ribeirão Preto , 2002.

[10]. Jing Dong and Shi-Hua Huang,"Low-reflective Surface Texturing for Large Area Multicrystalline Silicon Using NaOH-NaClO Solution", Surface Engineering and Applied Electrochemistry,2014, Vol-50, pp-2832.

[11]. KoichiroYamakawa, Yoshinori Sato and Katsuyuki Fukutani, "Asymmetric and symmetric absorption peaks observed in infrared spectra of $\mathrm{CO}_{2}$ adsorbed on $\mathrm{TiO}_{2}$ nanotubes", The Journal of Chemical Physics, vol-144, 2016, pp-154703-1 - 154703-7

[12]. Wei Zhanga, Abbas A. Dehghani-Sanijb, Richard S. Blackburna, "IR study on hydrogen bonding in epoxy resin-silica nanocomposites”, Progress in Natural Science, Vol-18, 2008, pp- 801-805.

[13]. E. A. V. Ebsworth, M. Onyszchuk, and N. Sheppar, "The Infrared 8pectra of the Methylsilyl Halides and Related Compounds", Journal of chemical society,1958, pp-1453-1460 .

[14]. Fan Bai, Wai-Keung and Zhifeng Huang, "Porosification-Induced Back-Bond Weakening in Chemical Etching of n-Si(111)", J. Phys. Chem. C, 2013, vol-117, pp- 2203-2209.

[15]. Avvaru Venkata Narasimha Rao, Veerla Swarnalatha, Ashok Kumar Pandey \& Prem Pal, "Determination of precise crystallographic directions on $\mathrm{Si}\{111\}$ wafers using self-aligning pre-etched pattern", Micro and Nano Systems Letters, vol-6, 2018.

[16]. Hsiao-Yen Chung, Chiun-Hsun Chen, and Hsin-Sen Chu, "Analysis of Pyramidal Surface Texturization of Silicon Solar Cells by Molecular Dynamics Simulations", International Journal of Photoenergy, Vol-2008, pp-6.

[17]. Tudor E. Scheul Edris Khorani Tasmiat Rahman Martin D.B. Charlton Stuart A. Boden. "Wavelength and angle resolved reflectance measurements of pyramidal textures for crystalline silicon photovoltaics", Prog Photovolt Res Appl. 2020;pp-1-10.

Funding statement: The work is funded by SERI-DST Gov of India

Conflict of Interest: I have read and understood the journal policy on declaration of interests and declare the research work is totally unique and don't copy from any other sources like journal paper and patents. No other conflicts to declare

Author contributions: Soma Ray, Anup Mondal, Utpal Gangopadhyay.

Compliance with ethical standards: This method for novel texturization is a unique work. Industry has already adopted the method for their pilot plant production scale.

Consent to participate: All the authors have full consent to participate

Consent for Publication: All the authors have full consent to publish the article. 

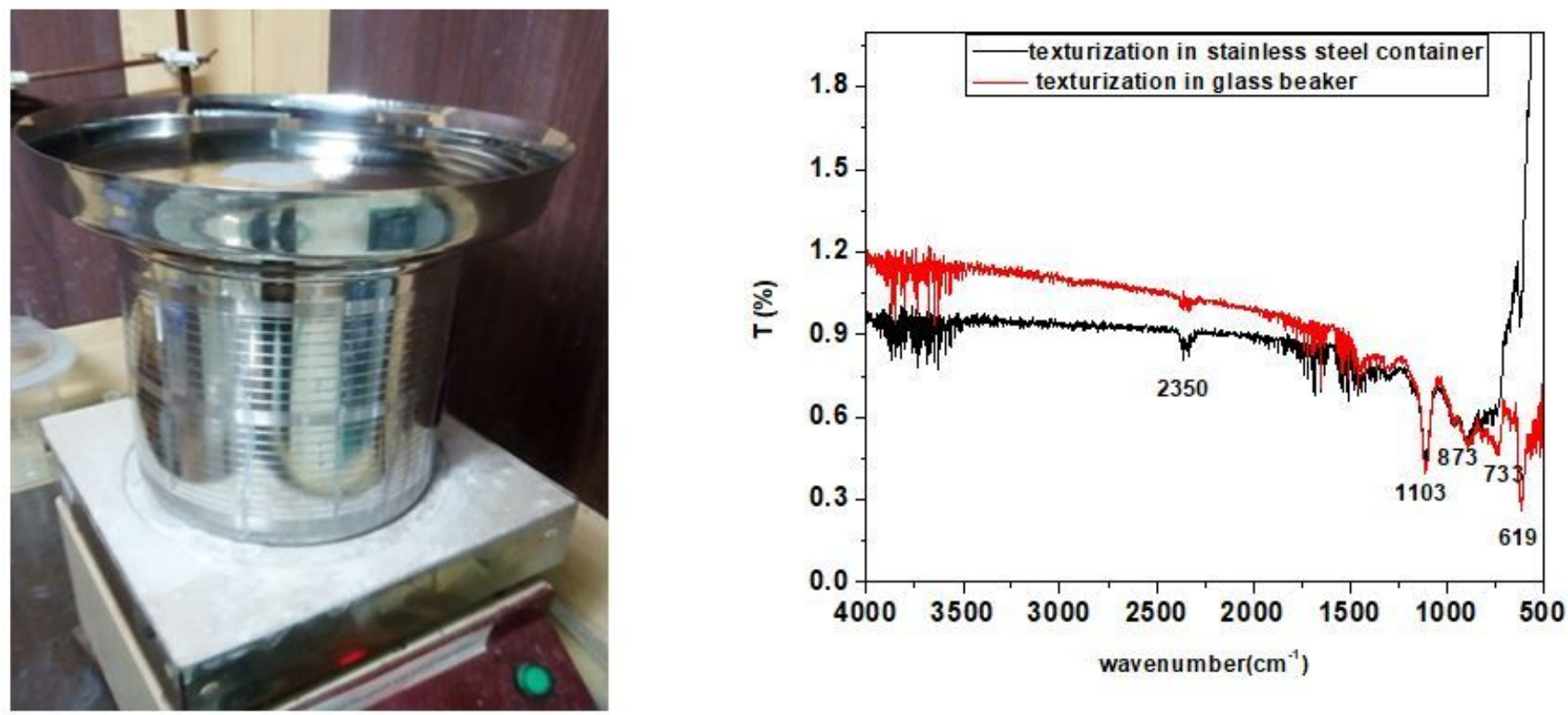

Figure 1

a. Steel can for texturization of wafers $(76.2 \mathrm{~mm} \times 76.2 \mathrm{~mm})$, b.FTIR analysis of diamond cut textured $\mathrm{n}$ type wafer in stainless steel and glass beaker
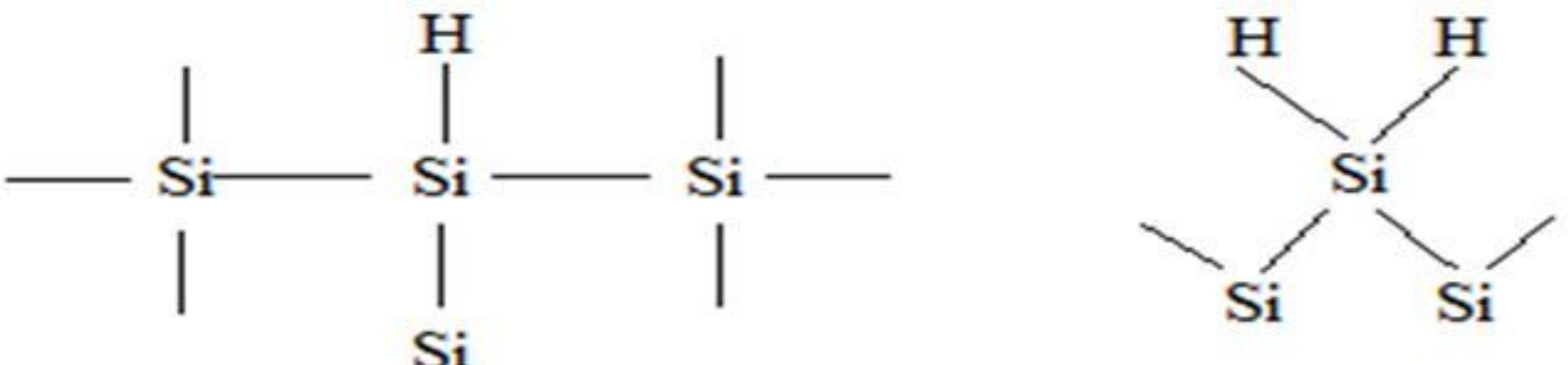

Figure 2

Bond structure of silicon(100) and (111) plane 

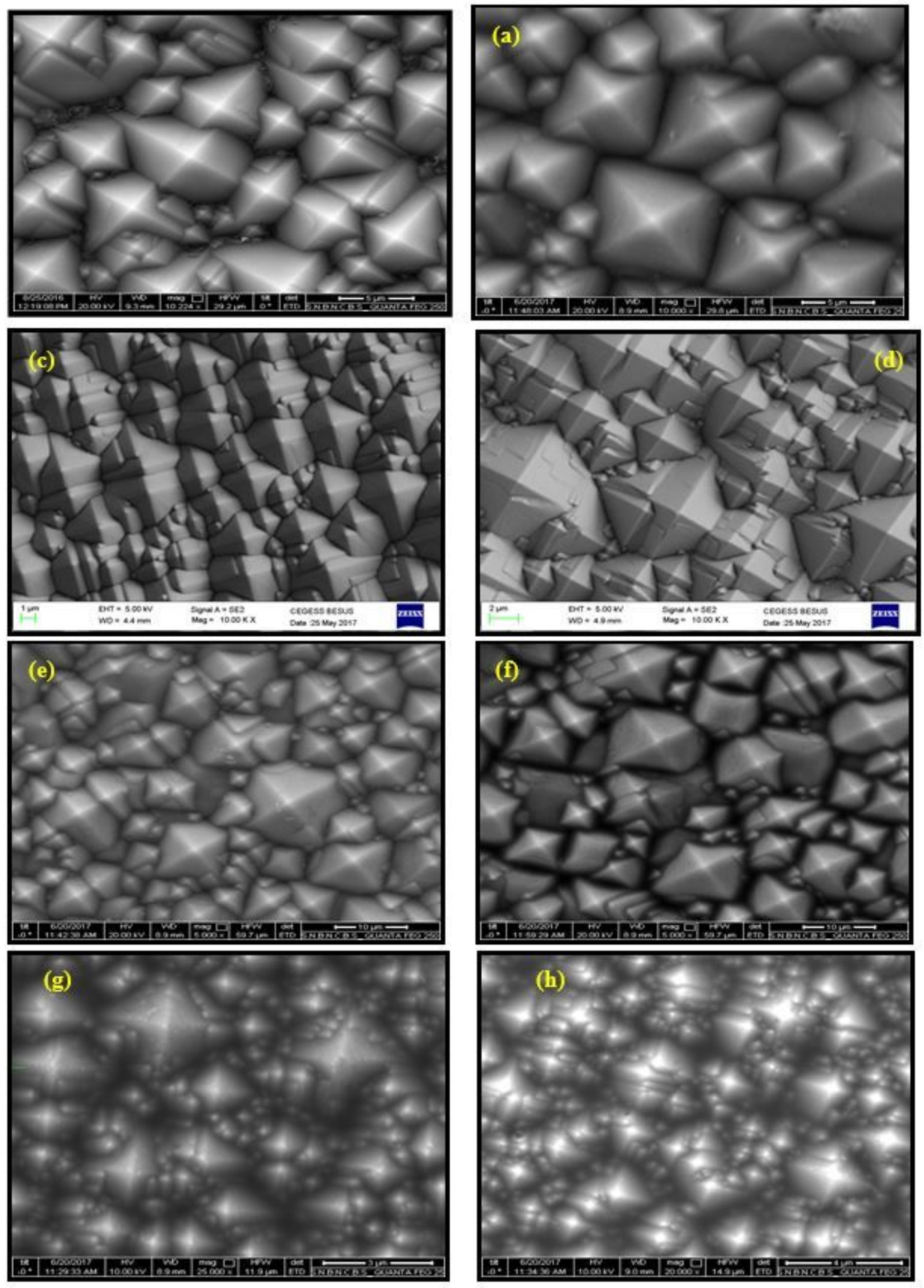

Figure 3

FESEM image of DWS textured sample in (a) batch 1, (b) batch 2, (c) batch 3, (d) batch 4, (e) batch 5, (f) batch $6,(\mathrm{~g})$ batch 7 and $(\mathrm{h})$ batch 8 . 

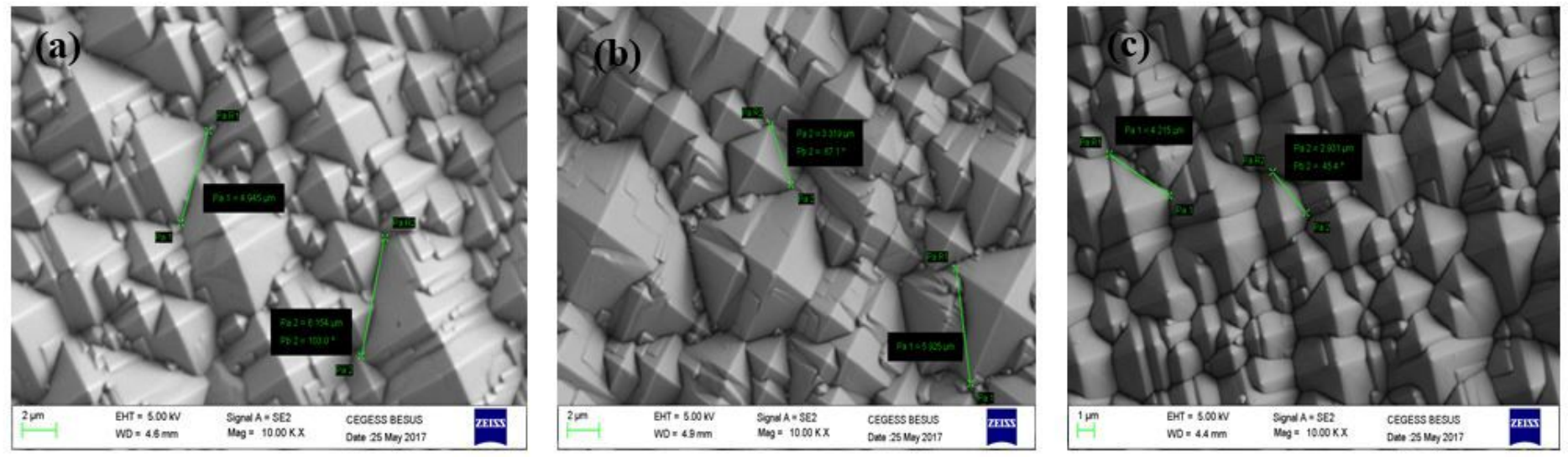

\section{Figure 4}

FESEM image of DWS textured sample in (a) day 1 batch 1, (b) day 2 batch 1, (c) batch 3 batch 1 .
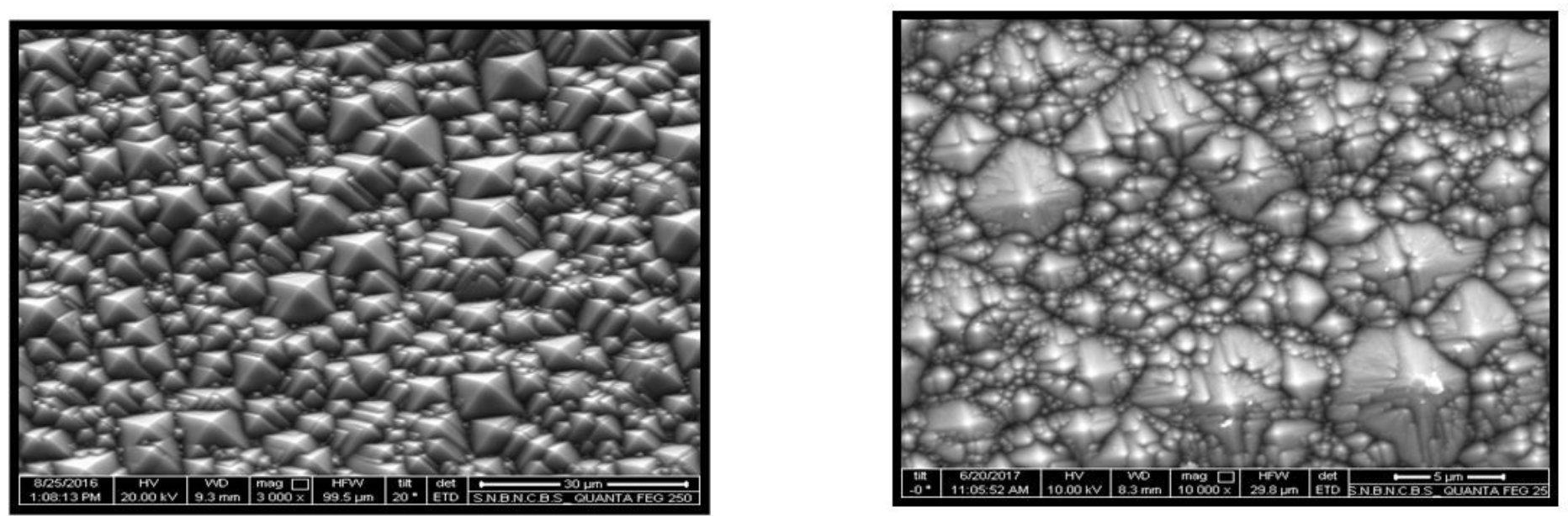

Figure 5

FESEM image of DWS textured sample by (a) our proposed method, (b) conventional texrization with SDR. 


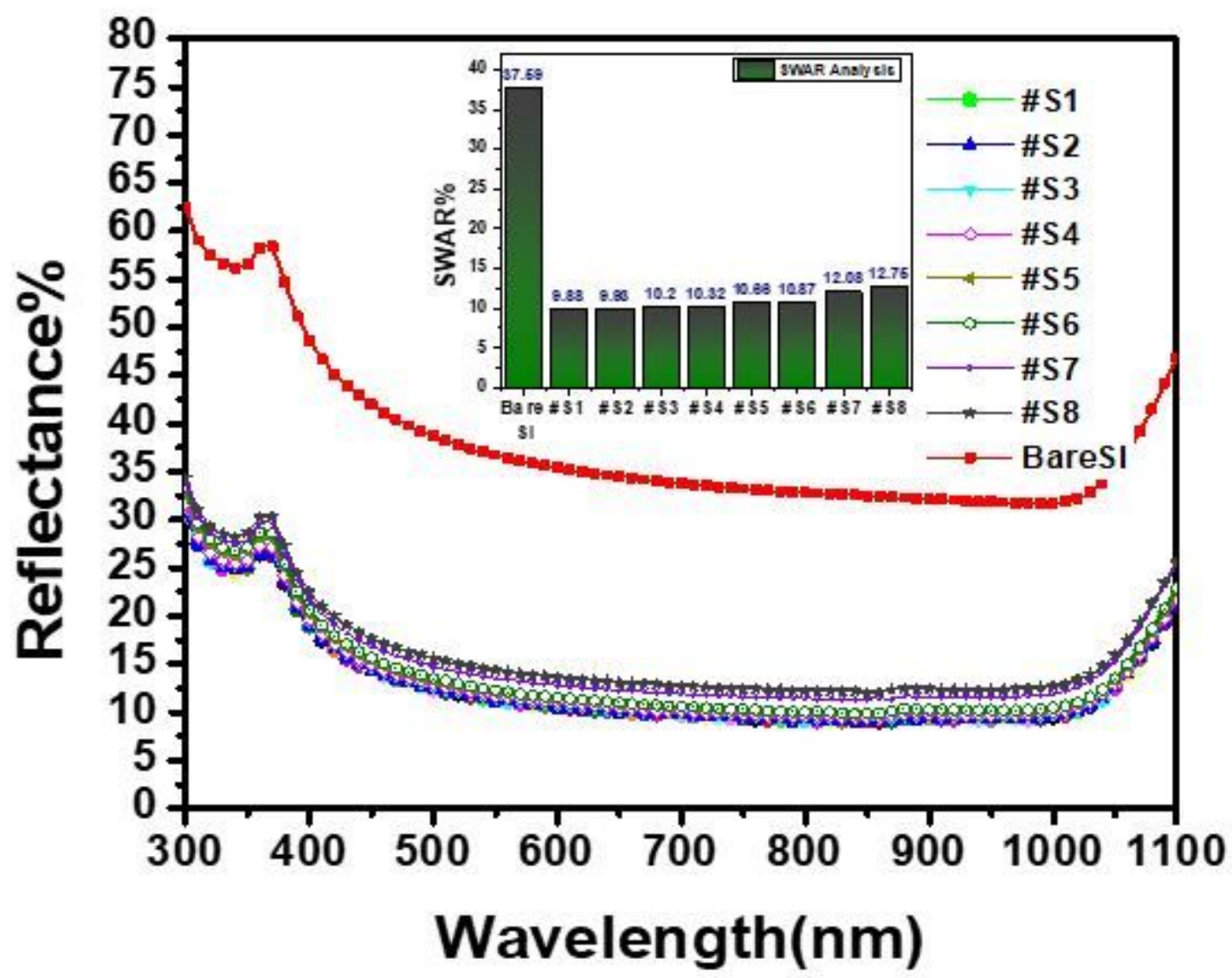

Figure 6

Variation of reflectance and SWAR analysis for DWS textured wafer for different batch; \#S1=batch1 sample, \#S2=batch2 sample, \#S3=batch3 sample, \#S4=batch4 sample, \#S5=batch5 sample, \#S5=batch1 sample, \#S6=batch6 sample, \#S7=batch7 sample and \#S8=batch8 sample. 


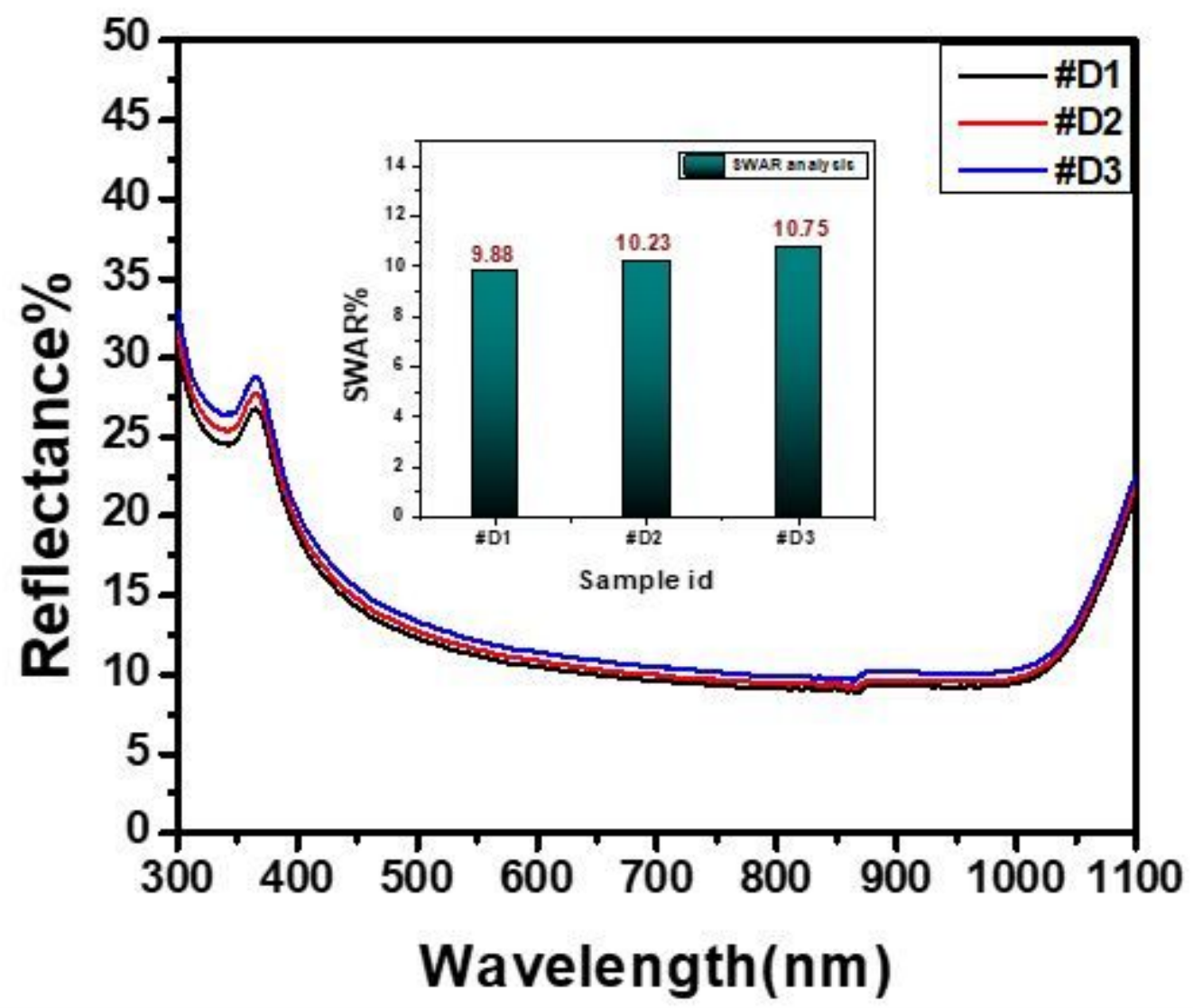

Figure 7

Variation of reflectance and SWAR analysis for DWS textured wafer for different day batch;\#D1= batch1 day1, ;\#D2= batch1 day2, ;\#D3= batch1 day3 . 


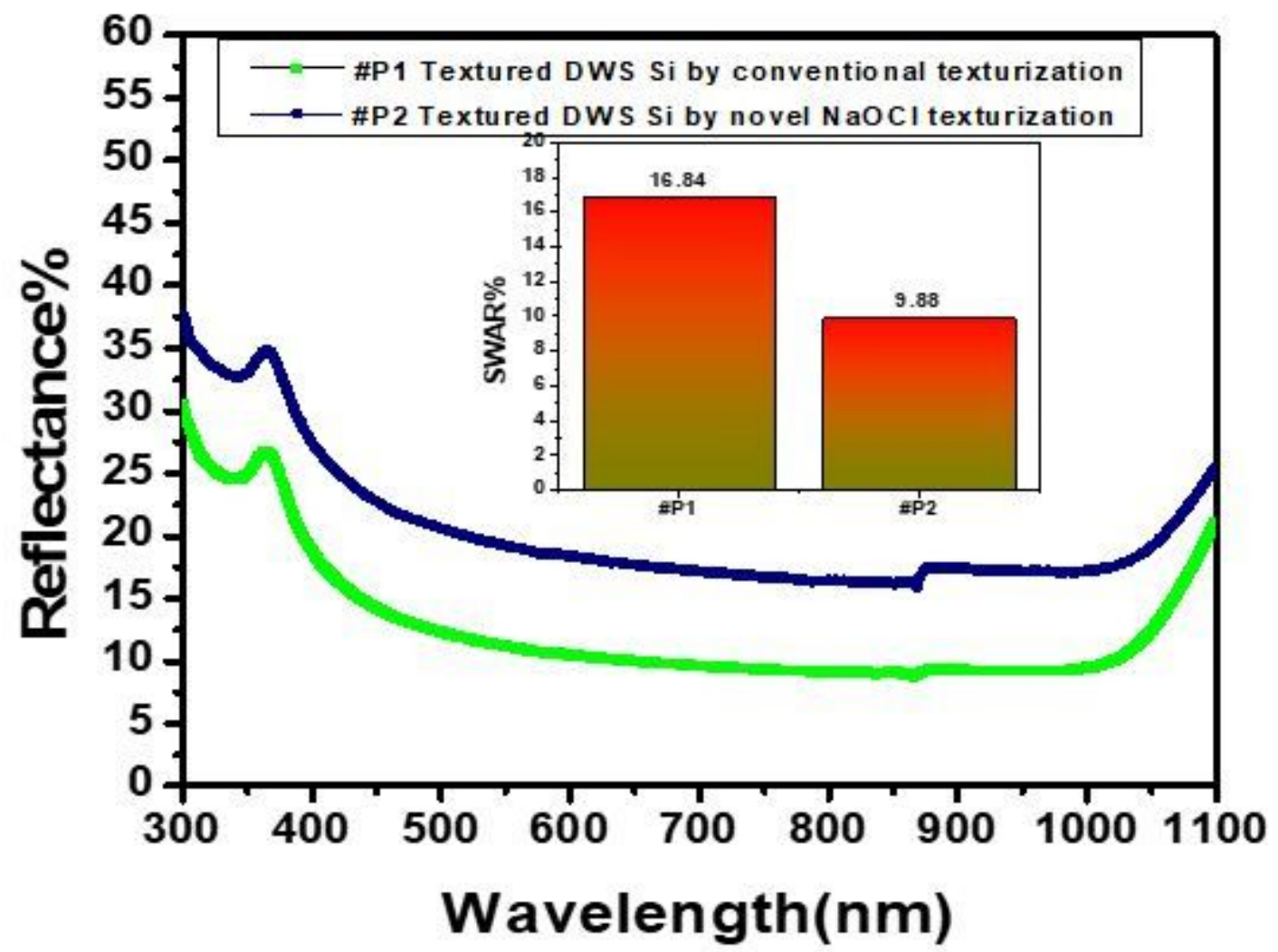

Figure 8

Comparison of reflection analysis between textured DWS silicon by conventional SWS texturization solution and our proposed novel solution.
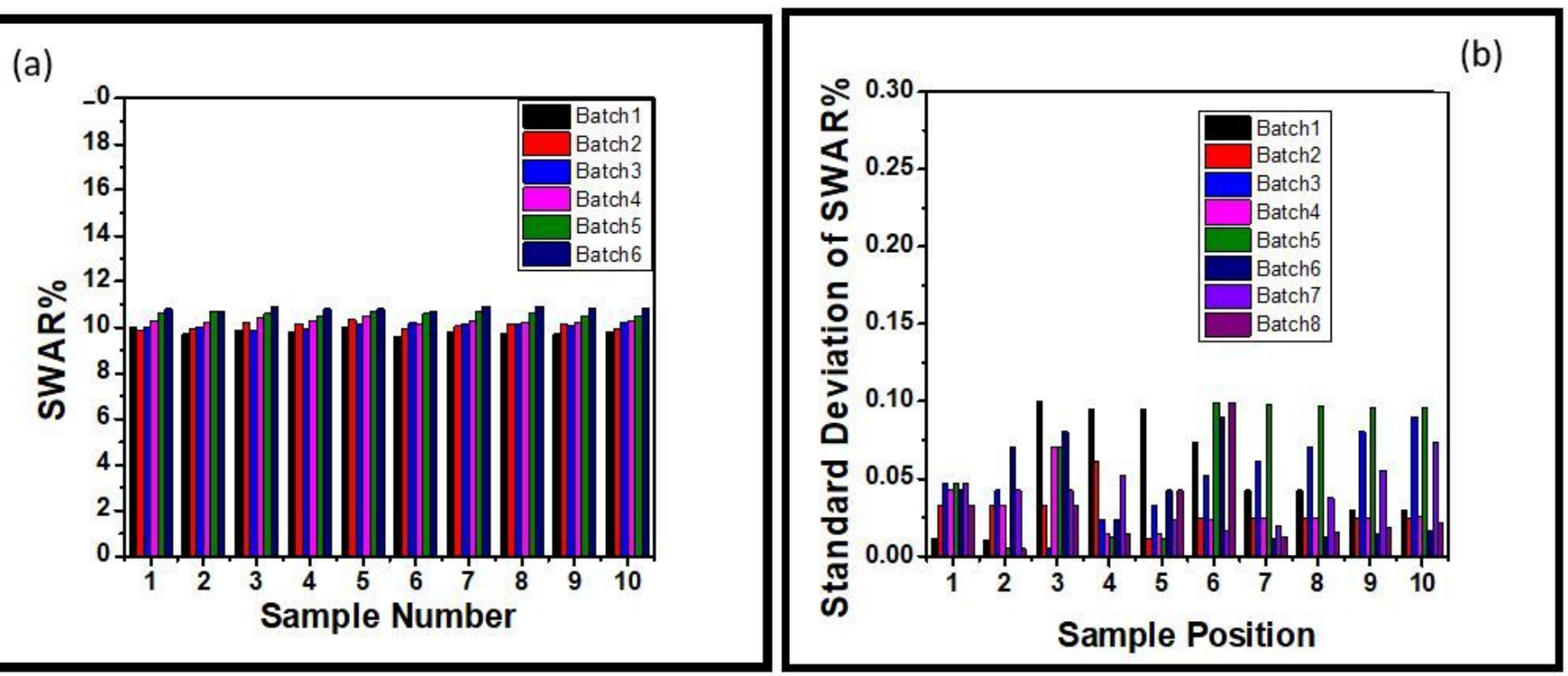
Figure 9

(a) Consistency and (b) uniformity taste of each batch process of texturization
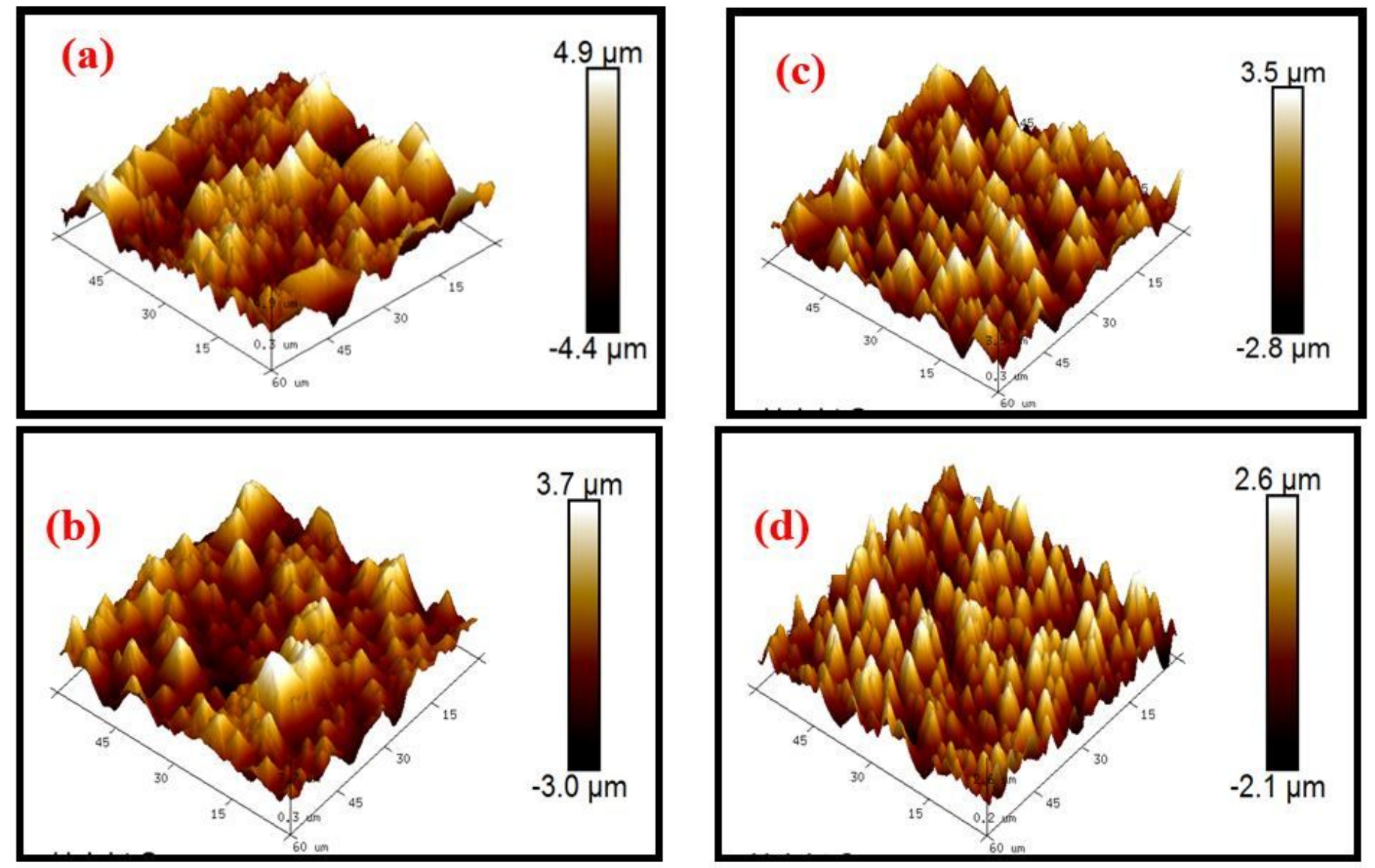

Figure 10

Typical AFM analysis of DWS textured samples (a) batch1 (b) batch3 (c) batch6 (d) batch7 
Results

- Peak to Peak Distance

- Minimum Peak Depth

- Maximum Peak Depth

Depth at Histogram Maximum

- Number Peaks Found

Results

- Peak to Peak Distance

- Minimum Peak Depth

- Maximum Peak Depth

- Depth at Histogram Maximum

- Number Peaks Found

Results

- Peak to Peak Distance

- Minimum Peak Depth

- Maximum Peak Depth

- Depth at Histogram Maximum

$\leftarrow$ Number Peaks Found

Results

- Peak to Peak Distance

Minimum Peak Depth

- Maximum Peak Depth

- Depth at Histogram Maximum

$\leftarrow$ Number Peaks Found
$510.959 \mathrm{~nm}$

$5522.77 \mathrm{~nm}$

$5012 \mathrm{~nm}$

$5522.77 \mathrm{~nm}$

160

$504.500 \mathrm{~nm}$

$4251.89 \mathrm{~nm}$

$3747 \mathrm{~nm}$

$3747.39 \mathrm{~nm}$

155

$178.621 \mathrm{~nm}$

$3379.91 \mathrm{~nm}$

$3559 \mathrm{~nm}$

$3558.53 \mathrm{~nm}$

151
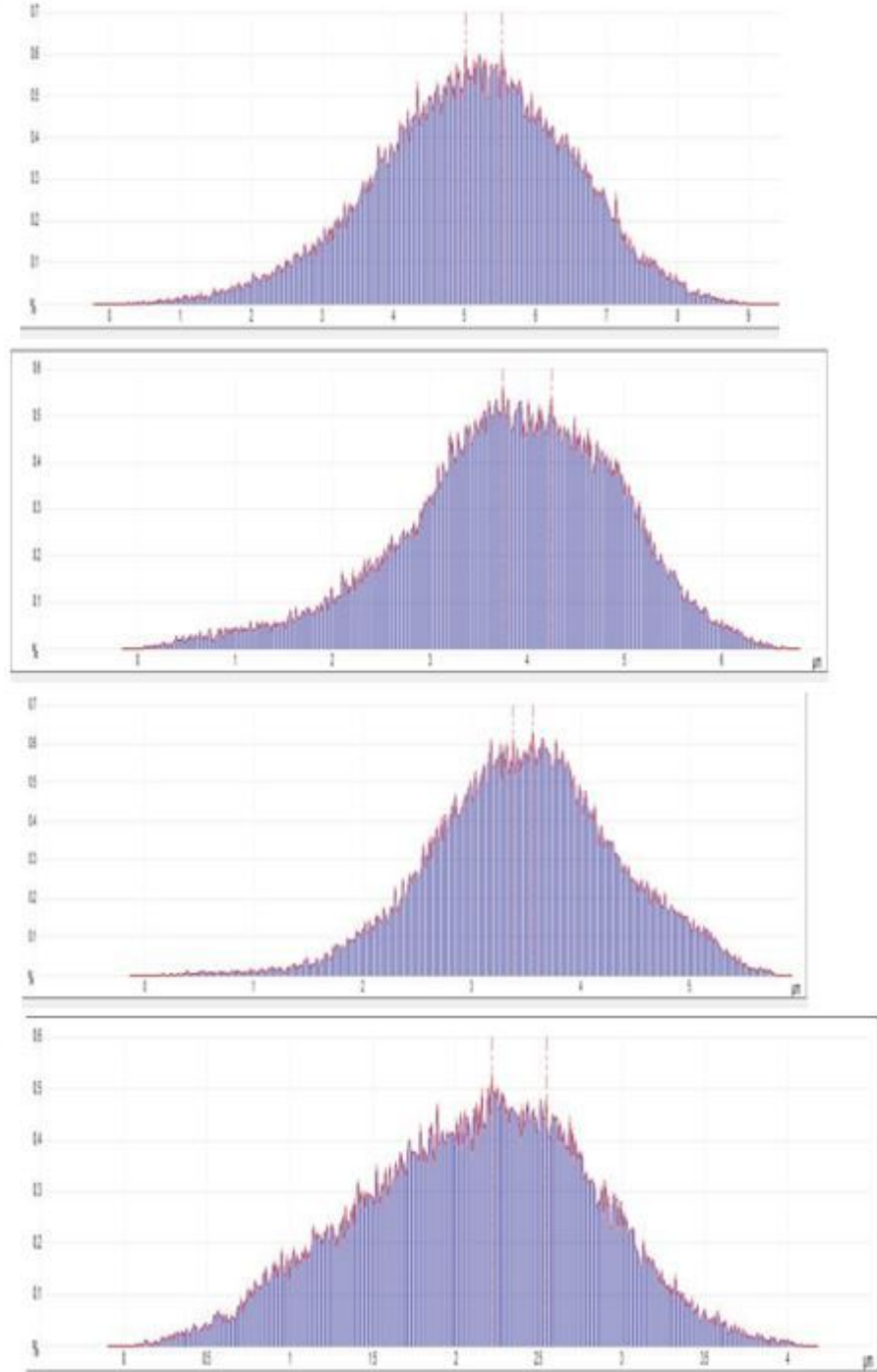

\section{Figure 11}

Depth analysis of DWS textured samples (a) batch1 (b) batch3 (c) batch6 (d) batch7 


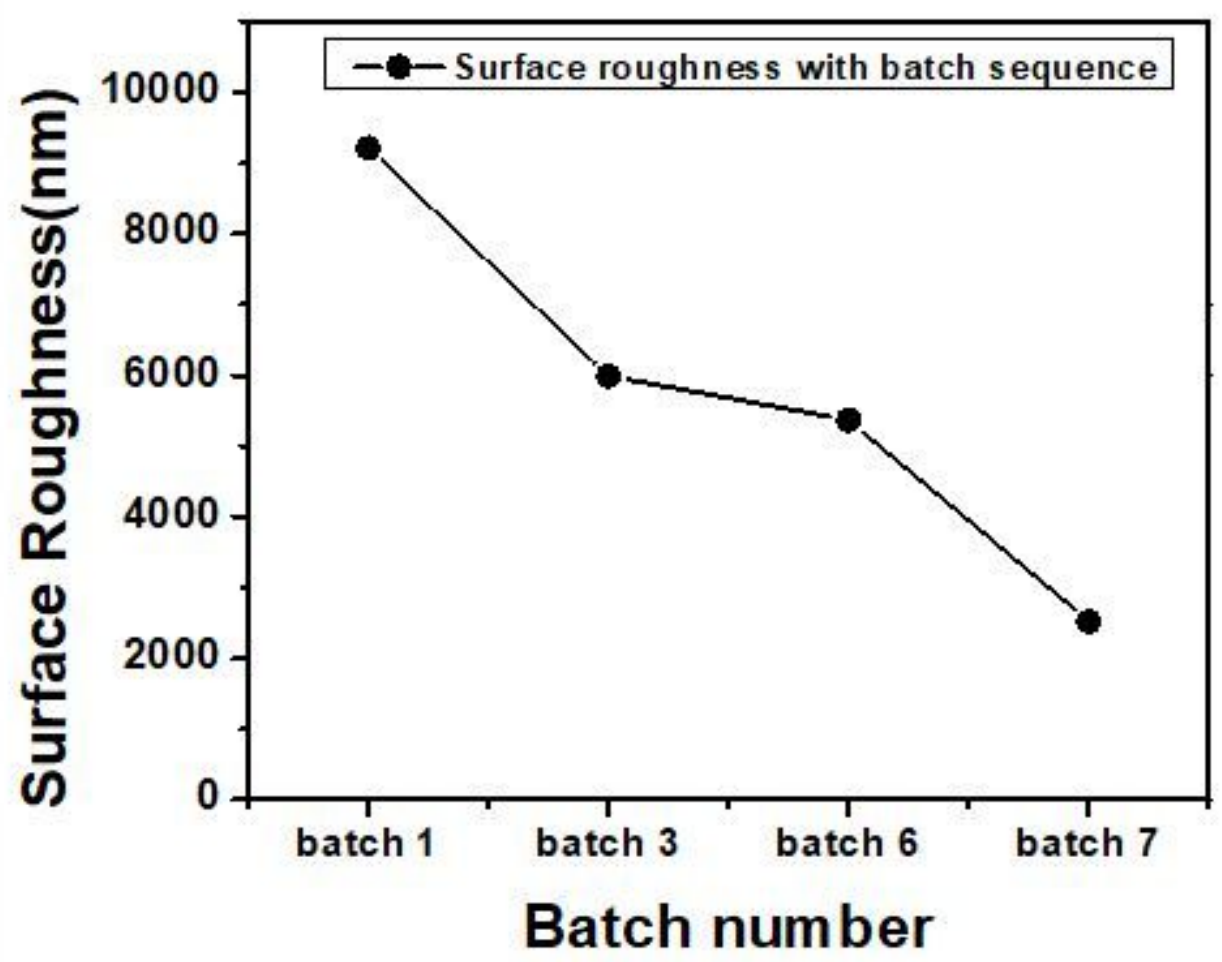

Figure 12

Typical Surface roughness study of DWS textured pyramids with the change in batch sequence
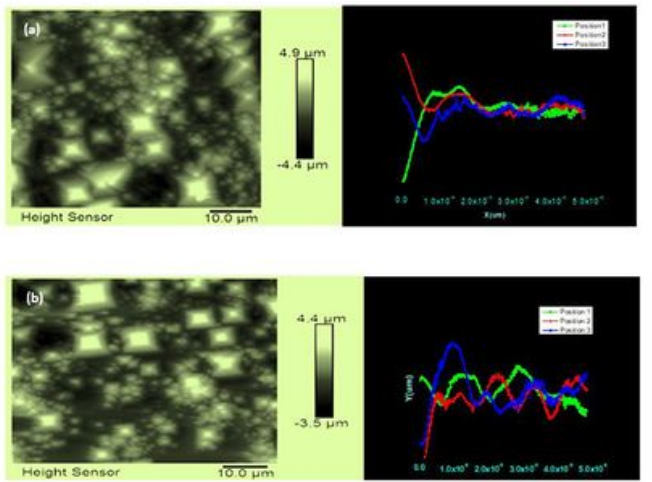
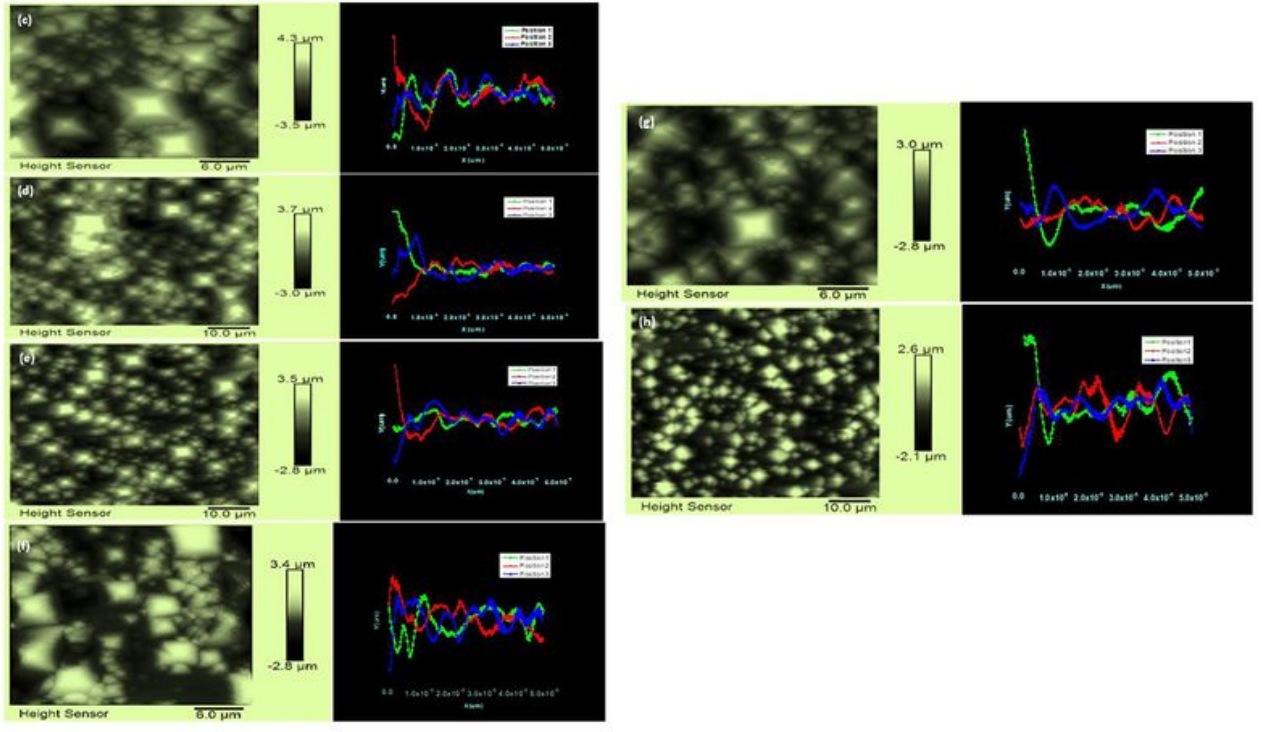

Figure 13 
AFM image analysis with periodicity of pyramid test for textured DWS wafer (a) batch1 (b) batch2 (c) batch3 (d) batch4 (e) batch5 (f) batch6 $(\mathrm{g})$ batch7 (h) batch8.

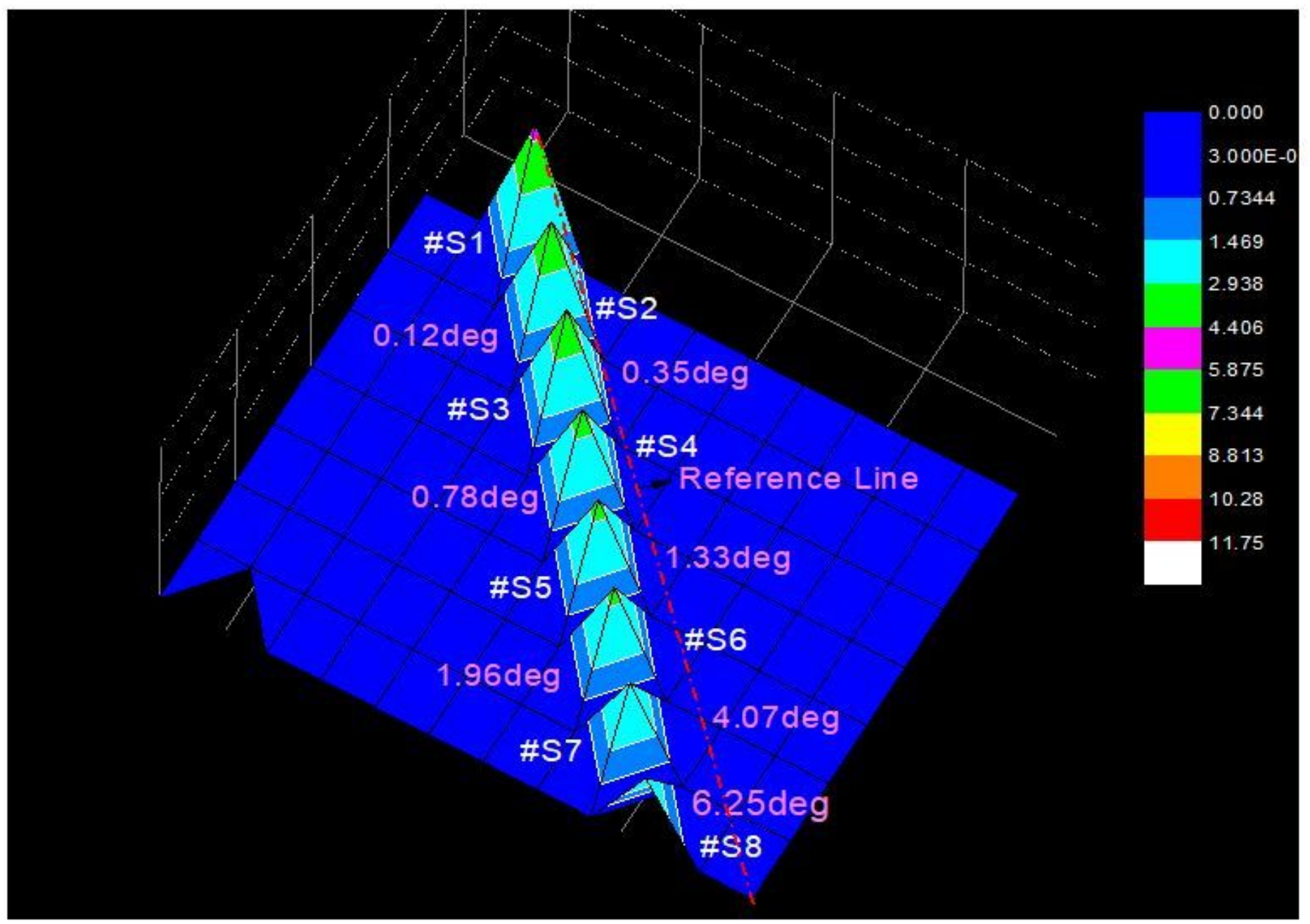

Figure 14

Pyramid tip inclination with advancement of batch 

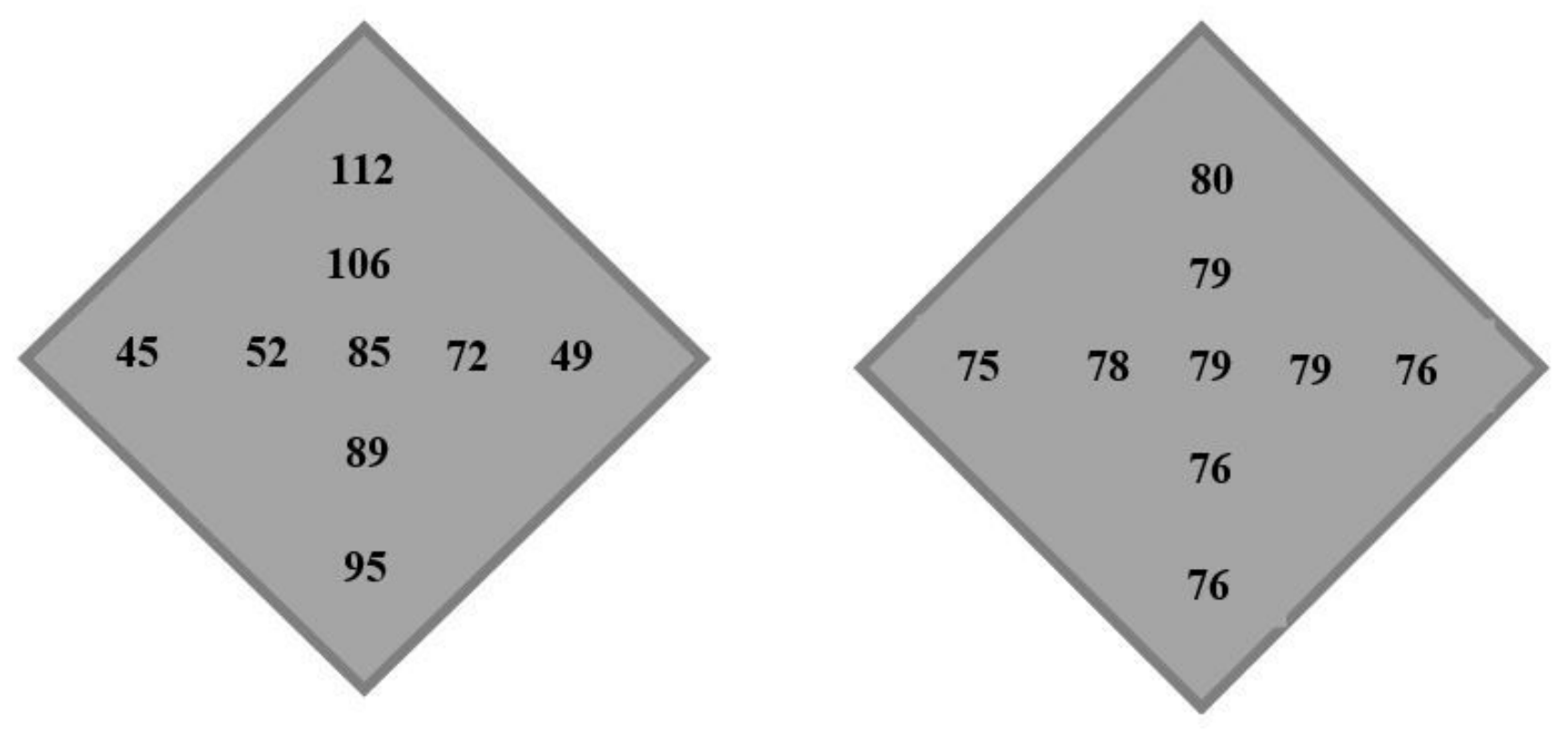

Figure 15

Sheet resistance analysis in $(\Omega / \mathbb{Q})$ for texturization with (a) $\mathrm{KOH}$ with saw damage removal (b) $\mathrm{KOH}$ with $\mathrm{NaOCl}$ without saw damage removal.
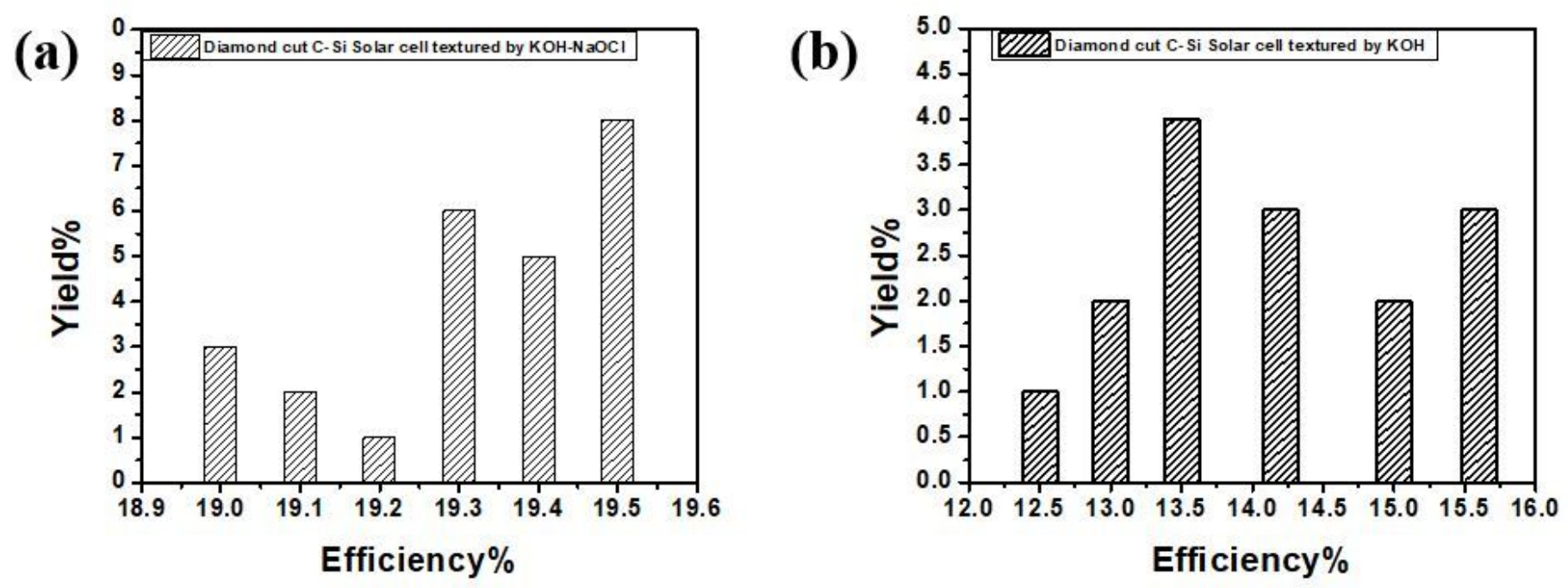

\section{Figure 16}

Variation of yield of efficiency for (a) diamond cut c-Si Solar cell textured by $\mathrm{KOH}-\mathrm{NaOCl}$ without saw damage removal, (b) diamond cut c-Si Solar cell textured by KOH with saw damage removal. 